\title{
Platelets and Inflammation
}

\section{Meinrad Gawaz, MD}

\section{Contents}

INTRODUCTION

The Platelet, the Inflammatory Cell

Receptors That Regulate Platelet Adhesion

TO INFLAMMATORY CELLS

Platelet-Derived Mediators That Modulate

Function of InFlammatory Cells

Platelet Interaction With the Endothelium

Platelet Interaction With Leukocytes

Platelets and Atherosclerosis

CONCLUSIONS

REFERENCES

\section{INTRODUCTION}

Platelets play a major physiological role in control of vascular integrity at the site of vascular lesions. However, the pathophysiological role of platelets is much broader than regulation of hemostasis and thrombosis. Platelets are critical elements in linking and modulating thrombosis, inflammation, and tissue repair. Platelets are stimulated by a variety of agonists including thrombin or ADP and also by inflammatory agents such as antibodies, complement, bacteria, and others. Platelets contribute to inflammation by interacting with inflammatory cells via adhesion and secretion of prestored proinflammatory mediators. Thus, platelets are critical elements in the pathophysiology of inflammation and modulate significantly a variety of inflammatory diseases. A profound understanding of the molecular mechanisms underlying the role of platelet in

From: Contemporary Cardiology:

Platelet Function: Assessment, Diagnosis, and Treatment

Edited by: M. Quinn and D. Fitzgerald (C) Humana Press Inc., Totowa, NJ 
inflammation may result in new therapeutic strategies in acute and chronic inflammatory diseases.

\section{THE PLATELET, THE INFLAMMATORY CELL}

The fundamental role of platelets is to maintain the vascular integrity and to prevent loss of blood at sites of vascular injury. Under physiological conditions platelets circulate in the artery branch without interacting with each other or with structures of the intact vessel wall (1). At the location of an endothelial disruption, subendothelial matrix proteins including collagen and von Willebrand factor (vWF) are exposed to circulating platelets that are recognized by specific platelet membrane receptors such as glycoprotein (GP)VI (2) or the plasma membrane complex GPIb-IX-V (3-5). Once adherent to the subendothelium, platelets spread on the surface and release granule-stored components that recruit additional platelets to the arterial lesion. In addition, adhering platelets express the activated form of the fibrinogen receptor GPIIb-IIIa that mediates platelet aggregation through formation of fibrinogen bridges between two adjacent platelets (6,7) (Fig. 1).

Despite regulation of hemostasis, platelets are involved in thrombosis and inflammation. Hemostasis, thrombosis, and inflammation are complex mechanisms with overlapping steps and connecting pathways. Interactions between platelets and inflammatory cells (e.g., endothelium, leukocytes) take place at various stages of the inflammatory process (8). They occur in the circulation as well as in extravascular inflammatory sites and are regulated through adhesion receptors and proinflammatory mediators that are released from internal stores of activated platelets. Platelets have been shown to be involved in inflammatory diseases caused by pathogens including bacteria, viruses, or parasites, leading to infectious endocarditis, sepsis, or the acquired thrombocytopenia that occurs during retroviral infections caused by the human immunodeficiency virus (HIV) and T-cell lymphotropic virus (9) (Table 1). In these diseases platelets participate in nonspecific immunodefense mechanisms caused by exogenous pathogens. Furthermore, platelets are involved in acute and chronic inflammation that is not directly related to infectious pathogens including diseases such as acute respiratory distress syndrome (ARDS), systemic inflammatory response syndrome, immune complex disease, allergic asthma, inflammatory bowel disease (10), multiple organ failure in septic shock $(11,12)$, organ dysfunction associated with cardiopulmonary bypass (13), or acute coronary syndromes (14) including acute myocardial infarction and reperfusion $(15,16)$ (Table 1). Moreover, platelets are fundamentally involved in chronic inflammatory 


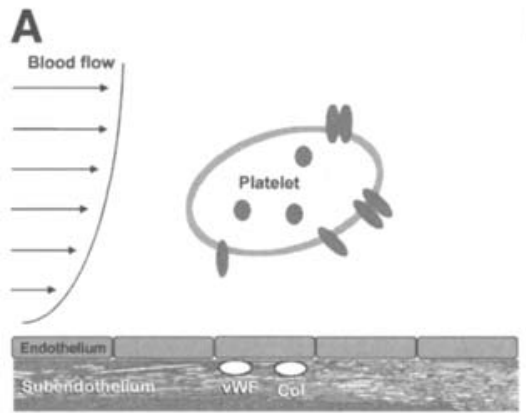

B
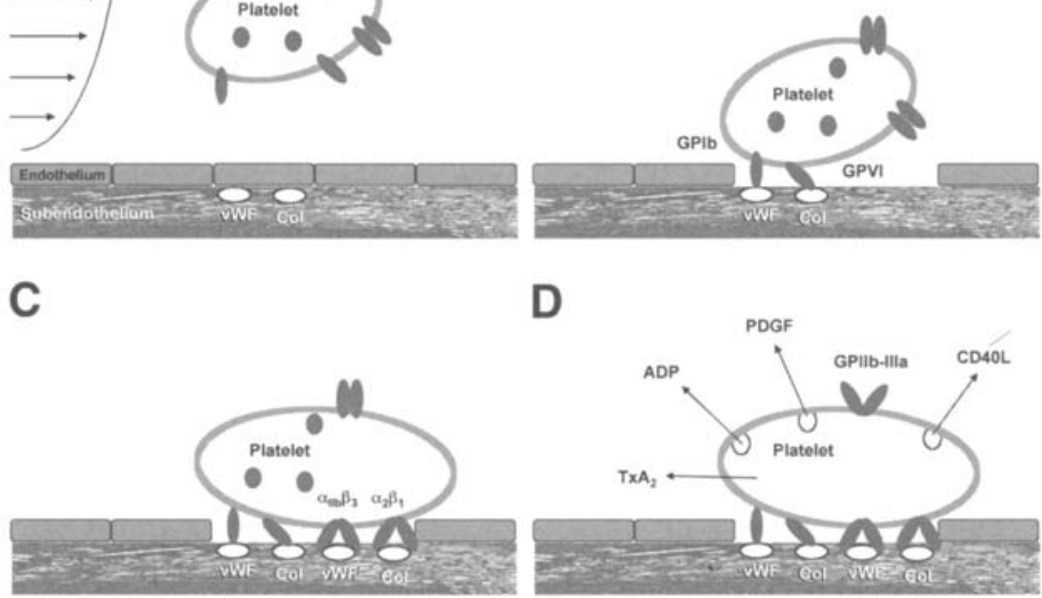

E
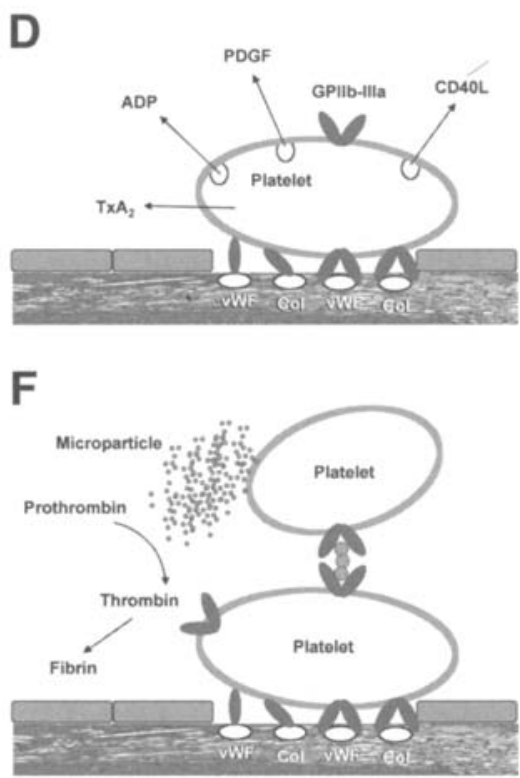

Fig. 1. (A) Platelet-dependent formation of a thrombus at an atherosclerotic plaque. Platelets do not adhere to the intact endothelial monolayer under physiological conditions. At the site of vascular lesions, extracellular matrix proteins like von Willebrand factor (VWF) and collagen (Col) are exposed to the blood. (B) Via the membrane adhesion receptors GPIb $\alpha$ and GPVI, platelets loosely adhere to the subendothelium. (C) This initial adhesion results in platelet activation and "opening" of the integrin receptors $\alpha_{\mathrm{IIb}} \beta_{3}$ (fibrinogen receptor) and $\alpha_{2} \beta_{1}$ (collagen receptor). The interaction of $\alpha_{\mathrm{II}} \beta_{3}$ and $\alpha_{2} \beta_{1}$ with extracellular matrix proteins stabilizes platelet adhesion (firm adhesion). (D) Subsequently, platelets spread and degranulate and thereby recruit additional platelets to the already adherent ones. (E) Platelets form microaggregates via fibrinogen "bridges" between two $\alpha_{\mathrm{II}} \beta_{3}$ receptors. (F) Formation of microparticles around the platelet aggregates catalyzes thrombin generation and thus fibrin formation that stabilizes the platelet thrombus. CD40L, CD40 ligand; PDGF, plateletderived growth factor; $\mathrm{TXA}_{2}$, thromboxane $\mathrm{A}_{2}$. 
Table 1

Role of Platelets in Inflammation

Inflammation caused by infection

Infectious endocarditis

Sepsis

Acquired idiopathic thrombocytopenia

Acute inflammation not directly related to infectious pathogens

Acute respiratory distress syndrome (ARDS)

Systemic inflammatory response syndrome (SIRS)

Multiple organ failure (MOF)

Immune complex disease

Allergic asthma

Cardiopulmonary bypass

Inflammatory bowel disease

Acute coronary syndrome (ACS)

Myocardial infarction and reperfusion

Chronic inflammation

Atherosclerosis

Development of vulnerable coronary plaque

Rheumatoid arthritis

Periodontitis

diseases including atherosclerosis $(17,18)$, progression, and induction of vulnerable coronary plaques leading to acute coronary syndrome (19), rheumatoid arthritis, or periodontitis (10) (Table 1). Thus, platelets are both target cell and effector in a variety of inflammatory diseases.

\section{RECEPTORS THAT REGULATE PLATELET ADHESION TO INFLAMMATORY CELLS}

The mechanisms of thrombosis and inflammation require a close interaction among platelets, endothelium, leukocytes, plasma coagulation factors, and structures of the vessel wall (extracellular matrix) (20). Adhesion processes that are regulated by numerous adhesion receptors play a major role in these mechanisms. Platelets express multiple glycoproteins on their membranes that mediate the interactions with other platelets, with endothelial cells, or with leukocytes $(21,22)$. Furthermore, platelet adhesion receptors mediate platelet attachment to subendothelial matrix proteins as well as interactions with plasmatic coagulation factors. Firm contact of platelets to cells or the vascular subendothelium enables platelets to localize a procoagulatory or inflammatory response in distinct locations of the vasculature (23). 
Table 2

Membrane Glycoproteins Involved in Platelet Adhesion to Inflammatory Cells

Platelet membrane glycoprotein

Ligand/counterreceptor

Integrins

$\begin{array}{lll}\alpha_{\text {IIb }} \beta_{3} & \text { (GPIIb-IIIa, CD41-CD61) } & \text { Fg, Fn, Vn, vWF, Ln } \\ \alpha_{v} \beta_{3} & \text { (vitronectin receptor, CD51-CD61) } & \text { Vn, Fg, Fn } \\ \alpha_{2} \beta_{1} & \text { (collagen receptor, CD49b) } & \text { Coll, Ln } \\ \alpha_{5} \beta_{1} & \text { (fibronectin receptor, CD49c) } & \text { Fn } \\ \alpha_{6} \beta_{1} & \text { (laminin receptor, CD49f) } & \text { Ln }\end{array}$

Leucin-rich glycoproteins
GPIb-V-IX
$(\mathrm{CD} 42 \mathrm{a}-\mathrm{b}-\mathrm{c})$
vWF, CD11b-CD18
GPIV
(CD36)
TSP-1

Selectins

P-selectin (CD62P)

Immunoglobulin-like adhesion receptors

ICAM-2

PECAM-1

JAM-1

JAM-3

GPVI

\section{PSGL-1}

$\mathrm{Fg}, \alpha_{\mathrm{L}} \beta_{2}$ (LFA-1, CD11a)

?

?

$\alpha_{M} \beta_{2}$ (MAC-1, CD11b)

Coll

Abbreviations: GP, glycoprotein; Fg, fibrinogen; Vn, vitronectin; Fn, fibronectin; Coll, collagen; Ln, laminin; vWF, von Willebrand factor; TSP, thrombospondin; ICAM, intercellular adhesion molecule; PECAM, platelet-endothelial cell adhesion molecule; JAM, junctional adhesion molecule; LFA, leukocyte function-associated antigen; PSGL, P-selectin glycoprotein ligand.

Platelets express a variety of major membrane glycoproteins that are classified into four groups according to their characteristic structures: integrins, leucine-rich glycoproteins, selectins, and receptors of the immunoglobulin-type (24) (Table 2). All platelet membrane receptors have been shown to recognize a counterligand (e.g., fibrinogen) or receptor (e.g., P-selectin) on the partner cell and to mediate intercellular, heterotypic adhesion.

\section{Integrins}

Integrins are adhesion receptors that link structures of the cytoskeleton to the extracellular matrix (25-27). Integrins are ubiquitous and can be found on almost all cells including platelets. In addition to platelet aggregation and adhesion, integrins participate in tissue development and differentiation as well as in the growth of atherosclerotic plaques and vascular remodeling. Integrins are noncovalently linked heterodimers 
consisting of $\alpha$ - and $\beta$-subunits. They are subdivided on the basis of the $\beta$-chain, which pairs with a specific $\alpha$-chain to form a functional receptor. To date $8 \beta$ - and $14 \alpha$-subunits have been identified (25). The $\beta$ subunit serves for the structural classification, and the $\alpha$-subunit determines the specificity. Integrins interact with numerous glycoproteins (e.g., collagen, fibronectin, fibrinogen, laminin, thrombospondin, vitronectin, and vWF) (Table 2). These glycoproteins are components of the extracellular matrix, but they also occur in solution in plasma. The $\beta_{1}$ - and $\beta_{3}$-integrins recognize the arginine-glycine-aspartate (RGD) amino acid sequence. The RGD sequence is a component of numerous extracellular matrix proteins and is also found in fibrinogen molecules. Synthetic peptides exhibiting the RGD sequence and having similar molecular structures are competitive inhibitors of ligand binding to integrins. Five different integrins have been described so far on platelets, three of the $\beta_{1}$-integrin class $\left(\alpha_{2} \beta_{1}\right.$ [collagen receptor], $\alpha_{5} \beta_{1}$ [fibronectin receptor], and $\alpha_{6} \beta_{1}$ [laminin receptor]) and two of the $\beta_{3}$-integrin family $\left(\alpha_{\mathrm{IIb}} \beta_{3}\right.$ [fibrinogen receptor] and $\alpha_{\mathrm{v}} \beta_{3}$ [vitronectin receptor]) (25) (Table 2 ).

GPIIb-IIIa $\left(\alpha_{\text {IIb }} \beta_{3}\right)$ belongs to the $\beta_{3}$-integrins and is specific for the platelet/megakaryocyte system. GPIIb-IIIa is the most frequently occurring membrane glycoprotein of blood platelets and is constitutively expressed on the surface membrane. A substantial portion of GPIIb-IIIa is also present in intracellular stores ( $\alpha$-granules and the open canalicular system) and can be translocated to the plasma membrane upon activation. The main task of GPIIb-IIIa is to bind fibrinogen to the activated platelet surface, which allows platelets to aggregate (homotype intercellular adhesion). Under physiological conditions, circulating platelets carry the resting, not activated GPIIb-IIIa complex on their surface (lowaffinity state) (27). In the unactivated form, GPIIb-IIIa can only bind immobilized, but not soluble, fibrinogen. Platelet activation leads to a rapid change in the conformation of the GPIIb-IIIa complex and thereby to the exposure of high-affinity fibrinogen binding sites (high-affinity state) (27). This allows binding of soluble fibrinogen to the platelet surface and initiates aggregation. Besides its role in platelet aggregation, GPIIb-IIIa mediates platelet adhesion to subendothelial matrix proteins (fibrinogen, vWF, vitronectin, and laminin). Additionally, the receptor interferes with endothelial cells (heterotype intercellular adhesion) via the formation of fibrinogen "bridges" between the platelet GPIIb-IIIa and the vitronectin receptor $\alpha_{\mathrm{v}} \beta_{3}$ expressed on the luminal aspect of endothelial cells (27).

Whereas GPIIb-IIIa is specific for platelets and megakaryocytes, the vitronectin receptor $\left(\alpha_{\mathrm{v}} \beta_{3}\right)$ is found on many different types of cells 
including platelets, endothelial cells, and smooth muscle cells (7). Like GPIIb-IIIa $\left(\alpha_{\mathrm{IIb}} \beta_{3}\right)$, the vitronectin receptor $\left(\alpha_{v} \beta_{3}\right)$ possesses the $\beta_{3^{-}}$ chain but this is paired with a different $\alpha$-chain $\left(\alpha_{v}\right)(7)$. In contrast to GPIIb-IIIa, the vitronectin receptor occurs in only very low amounts in platelets ( 50 receptors per platelet) and plays a very minor role in platelet function (7). The vitronectin receptor also binds other RGD-containing glycoproteins such as fibrinogen, fibronectin, $\mathrm{vWF}$, and thrombospondin (Table 2). $\alpha_{v} \beta_{3}$ contributes to the adhesion and migration of endothelial and smooth muscle cells to the extracellular matrix (7). Like GPIIb-IIIa, $\alpha_{v} \beta_{3}$ possesses a binding site for the RGD sequence but not for the KQAGDV sequence. When $\alpha_{v} \beta_{3}$-positive cells adhere to specific matrix proteins, the receptors are enriched in the region of focal contact sites (clustering). The vitronectin receptor plays a role in angiogenesis, apoptosis, and proliferation $(7,28)$. Inhibition of $\alpha_{v} \beta_{3}$ by antagonists reduces the migration and proliferation of smooth muscle cells-mechanisms that participate in atherogenesis and intima proliferation. $\alpha_{v} \beta_{3}$ is also expressed on the luminal side of endothelial cells and mediates the adhesion of activated platelets to endothelial cells. Besides the two $\beta_{3^{-}}$ integrins, platelets possess three $\beta_{1}$-integrins that seem to regulate the primary adhesion of platelets to the subendothelial matrix of the injured vessel wall. However, the exact role of $\beta_{1}$-integrins in hemostasis or thrombosis remains to be determined (7).

\section{Leucine-Rich Glycoproteins}

Platelets contain two membrane glycoprotein complexes, GPIb-IX-V and GPIV, which are characterized by their abundance of the amino acid leucine (3-5). The GPIb-IX-V complex forms the adhesion receptor for $\mathrm{vWF}$ and plays a central role in primary hemostasis. The main task of GPIb-IX-V is the adhesion of circulating platelets to vWF immobilized in collagen fibrils in spite of the significant shear forces that exist in regions of arterial flow. The GPIb-IX-V complex consists of four subunits. GPIb $\alpha(150 \mathrm{kDa})$ and $\mathrm{GPIb} \beta(27 \mathrm{kDa})$ are covalently linked to each other by disulfide bridges. Each GPIb molecule binds noncovalently to a GPIX molecule at a ratio of 1:1. GPV $(82 \mathrm{kDa})$ is the central unit of the receptor complex and is surrounded by two GPIb and two GPIX proteins linked noncovalently with one another. All subunits of the GPIbIX-V complex exhibit leucine-rich regions, whose functions are mostly unknown. The GPIb $\alpha$ subunit is very significant for the receptor function. In the region of the extracellular domain, GPIb $\alpha$ possesses binding sites for vWF and thrombin. The cytoplasmic domain anchors GPIb $\alpha$ in the cytoskeleton. Recent data indicate that GPIb $\alpha$ on platelets is a potential counterreceptor for Mac-1 (29). Furthermore, GPIb $\alpha$-associated 
vWF has also been proposed as a mediator of platelet-endothelium adhesion (30).

\section{Selectins}

Selectins are vascular adhesion receptors that mediate the heterotype interactions of cells. The molecular structure of selectins is characterized by an extracellular lectin domain with a neighboring epidermal growth factor-like domain followed by short regions that are homologous to the regulatory complement factors $(31,32)$. Three selectins have been described $(31,32)$. E-selectin occurs on cytokine-activated endothelial cells and modulates granulocyte adhesion. Resting endothelial cells do not contain any E-selectin. L-selectin occurs constitutively on leukocytes, is shed from the leukocyte surface after activation, and participates in the adhesion of leukocytes to endothelial cells $(31,32)$. Pselectin is found in platelets and endothelial cells, where it is stored in thrombocytic $\alpha$-granules and endothelial Weibel-Palade bodies, respectively. P-selectin is not expressed on the surface of resting platelets or endothelial cells. However, activation leads to the rapid release and surface expression of P-selectin on both types of cells. Both endothelial $\mathrm{P}$-selectin and $\mathrm{P}$-selectin exposed on activated adhering platelets at sites of endothelial disruption mediate initial tethering and rolling of leukocytes through their P-selectin glycoprotein ligand-1 (PSGL-1) $(33,34)$. $\mathrm{P}$-selectin binding to leukocytes induces activation of Mac-1 and allows firm adhesion and transplatelet migration (34).

\section{Immunoglobulin-Type Receptors}

Several immunoglobulin-type receptors have been described on platelets including platelet-endothelial cell adhesion molecule-1 (PECAM1) (6), intercellular adhesion molecule-2 (ICAM-2) (35), and junctional adhesion molecule-1 and -3 (JAM-1 and -3) (36-38). PECAM-1 occurs in platelets as well as in endothelial cells, neutrophils, and monocytes (6). The receptor appears to play a part in platelet adhesion to the subendothelium and to leukocytes by binding to glycosaminoglycans on their membrane. ICAM-2 has been described on activated platelets (35). The JAMs are newly discovered members of the Ig superfamily, which mediate cell-cell adhesion. Platelets contain at least two members of the JAM family including JAM-1 and JAM-3 (36). Platelet JAM-1 might be involved in primary hemostasis as the crosslinking of JAM-1 with Fc $\gamma$ RII resulted in platelet aggregation (27). It is also proposed to mediate platelet adhesion to cytokine-inflamed endothelial cells (39). Platelet JAM-3 has been recently shown to serve as a counterreceptor for Mac1-mediated platelet-leukocyte interactions (38). 


\section{PLATELET-DERIVED MEDIATORS THAT MODULATE FUNCTION OF INFLAMMATORY CELLS}

Chemotaxis is a central mechanism to recruit inflammatory cells to a site of tissue damage or repair (40). Platelets exert an important influence on the chemotaxis of other cells. During adhesion, platelets are activated and release a variety of potent chemotactic factors that are either stored in their granules or cytoplasm or synthesized after stimulation $(41,42)$. Moreover, platelets may by direct cell contact modulate the chemotactic properties of other cells including leukocytes $(43,44)$ and endothelium $(45,46)$. Platelets contain three different forms of storage granules: dense bodies or dense granules, $\alpha$-granules, and lysosomes. The granules are characteristic for platelets and serve as storage sites for proteins and other low-molecular-weight compounds (Table 3).

\section{Dense Granules}

The dense granules are named after their characteristic electron-optical density and contain high levels of adenine and guanine nucleotides, divalent cations, and serotonin. Thus, during the release reaction, prothrombotic constituents are liberated that recruit other platelets to adhere and aggregate. Serotonin (5-hydroxytryptamine) acts predominantly as a local vasoconstrictor and proinflammatory compound. Serotonin has been proposed to enhance the chemotactic responsiveness of human leukocytes (47). Stimulation of monocytes through serotonin induces secretion of lymphocyte chemoattractant activity (interleukin16 [IL-16]) that may promote the recruitment of $\mathrm{T}$ lymphocytes into an inflammatory focus $(48,49)$. Other dense-granule constituents (histamine, ATP) have been shown to support the proinflammatory reaction in the microenvironment of platelet adhesion (41).

\section{$\alpha$-Granules}

$\alpha$-Granules represent the major granule population in size and number (42). The $\alpha$-granules are typical secretatory vesicles that carry proteins to the cell surface to be released. Some of the released intragranular proteins adhere to the platelet surface or become integrated into the plasma membrane, and some diffuse into the extracellular fluid (Table $3)$. Two specific platelet proteins, $\beta$-thromboglobulin ( $\beta$-TG) and platelet factor-4 (PF-4) are localized in $\alpha$-granules together with proteoglycans (50). The latter include a family of $\beta$-TG-antigen molecules consisting of the platelet basic protein (PBP), connective tissueactivating protein-III (CTAP-III), and neutrophil-activating protein-2 (NAP-2), which are all precursors of $\beta$-TG and PF-4. Purified PF-4 lacks 
Table 3

Platelet-Derived Vasoactive, Proinflammatory, and Mitogenic Constituents

Dense granule

Serotonin (5-HT)

Adenine nucleotides: ATP, ADP

Guanine nucleotides: GTP, GDP

Histamine

$\alpha$-Granule

$\beta$-Tromboglobulin ( $\beta$-TG), platelet factor-4 (PF-4)

Platelet basic protein (PBP), connective tissue-activating protein III (CTAPIII), neutrophil-activating protein-2 (NAP-2)

Epithelial neutrophil-activating protein-78 (ENA-78)

Platelet-derived growth factor (PDGF)

Transforming growth factor- $\beta$ (TGF- $\beta$ )

Endothelial cell growth factor (ECGF)

Epidermal growth factor (EGF)

Vascular endothelial growth factor (VEGF)

Insulin-like growth factor (IGF)

Basic fibroblast growth factor (bFGF)

Metalloproteinases 2 and 9

Lysosome

Acid proteases

Glycohydrolases

Cytosol

Interleukin-1 $\beta$ (IL-1 $\beta$ )

CD40 ligand (CD40L)

Lipid mediators

Platelet-activating factor (PAF)

Thromboxane $\mathrm{A}_{2}\left(\mathrm{TXA}_{2}\right)$

Prostaglandin $\mathrm{E}_{2}\left(\mathrm{PGE}_{2}\right)$

Lysophosphatidic acid (LPA)

Sphingosine-1 phosphate (SP-1)

Microparticles

chemotactic activity for leukocytes but costimulation of leukocytes with tumor necrosis factor (TNF)- $\alpha$ results in exocytosis of secondary granule markers or tight adhesion to different surface proteins (51). PF-4 not only affects neutrophils, but it also induces the release of histamine by basophils and plays a role in eosinophil adhesion (42). $\beta$-TG represents a chemokine for neutrophils, monocytes, and lymphocytes.

Epithelial neutrophil-activating protein-78 (ENA-78) is another $\alpha-$ granule constituent that stimulates neutrophil activation (52). Among the mitogenic factors present in platelet $\alpha$-granules, the specific platelet- 
derived growth factor (PDGF) is present together with transforming growth factor- $\beta$ (TGF- $\beta$ ), endothelial cell growth factor (ECGF), epidermal growth factor (EGF), vascular endothelial growth factor (VEGF), vascular permeability factor (VPF), basic fibroblast growth factor (bFGF), and insulin-like growth factor (IGF) (52). PDGF and TGF- $\beta$ are growth factors that exert chemotactic properties on smooth muscle cells, macrophages, monocytes, and fibroblasts (52). Recently, PDGF and TGF- $\beta$ have been found to induce expression of VEGF in smooth muscle cells (53); VEGF is an endothelial mitogen and chemokine that stimulates endothelial cell migration. Furthermore, VEGF has been shown to support transendothelial migration of monocytes and to be chemotactic for mast cells, as well as monocytes. The chemokines RANTES and macrophage inflammatory protein- $1 \alpha(\mathrm{MIP}-1 \alpha)$ belong to the $\mathrm{CC}$ chemokines and are potent chemokines for basophils, eosinophils, $\mathrm{T}$ lymphocytes, and monocytes (52).

\section{Lysosomes}

Lysosomes contain enzymes such as acid proteases and glycohydrolases that may participate in inflammation and extravasation of leukocytes through their cytotoxic and proteolytic activity at sites of platelet accumulation at inflamed tissue (54) (Table 3).

\section{Cytosol}

Other important proinflammatory mediators such as IL-1 $\beta$ and CD40 ligand (CD40L) are present in the cytosol, are generated from mRNA, and are release upon activation (55). IL- $1 \beta$ is a central mediator in the cytokine cascade and is a potent activator of vascular cytokine production $(55,57,58)$. CD $40 \mathrm{~L}$ is structurally related to TNF- $\alpha$ and translocates within seconds of activation to the platelet surface $(46,56)$. CD40L stimulates endothelium to express ICAM-1, VCAM-1 and E-selectin, thus modulating leukocyte-endothelium interaction (46). Moreover, CD40L stimulates platelet secretion and stabilizes platelet aggregation by interference with GPIIb-IIIa (59).

\section{Lipid Mediators}

In addition to granule- and cytoplasma-stored substances, platelets release lipid mediators upon activation including platelet-activating factor (PAF), thromboxane $\mathrm{A}_{2}\left(\mathrm{TXA}_{2}\right)$, prostaglandin $\mathrm{E}_{2}\left(\mathrm{PGE}_{2}\right)$, platelet-derived lysophosphatidic acid (LPA), and sphingosine-1-phosphate (SP-1) (60). PAF is a phosphoglyceride generated from the phospholipids of cell membranes. PAF promotes leukocyte-endothelium interaction and favors diapedesis of leukocytes $(61)$. TXA $_{2}$ is another potent 
platelet mediator derived from the platelet membrane. Upon platelet activation $\mathrm{TXA}_{2}$ is synthesized de novo from arachidonic acid through the action of platelet cyclooxygenase- $1(\mathrm{COX}-1)$, an enzyme that is inhibited irreversibly by aspirin (62). $\mathrm{TXA}_{2}$ is known to induce platelet aggregation at sites of platelet activation. In addition, the arachidonic acid metabolite acts as a potent proinflammatory mediator, inducing leukocyte adhesion to and migration across activated endothelial cells (62). Another rich source of proinflammatory arachidonic acid metabolites is the platelet microparticles, membrane blebs that are shed from the surface of activated platelets by membrane vesiculation (63). Platelet microparticles have been shown to increase the adhesion of monocytes to endothelial cells in a time- and dose-dependent manner (63). In line with this finding, microparticle-derived arachidonic acid enhanced the expression of ICAM-1 on resting endothelial cells and upregulated CD11a/CD18 as well as CD11b/CD18 on monocytes.

Another potent inflammatory mediator, which is released in high amounts by activated platelets, is the cellular phospholipid LPA (64). LPA also leads to the activation of nuclear factor- $\mathrm{KB}(\mathrm{NF}-\mathrm{\kappa B})$ in endothelial cells, induces the upregulation of endothelial adhesion molecules, such as E-selectin and ICAM-1, and initiates the release of MCP-1 and IL-8 (64). Hence, LPA released during platelet-endothelial cell interactions at sites of endothelial dysfunction could function in a paracrine manner, directly modulating inflammatory and proliferative responses in the vascular wall.

\section{PLATELET INTERACTION WITH THE ENDOTHELIUM}

The vascular endothelium is central for maintaining homeostasis. Endothelial cells produce and present molecules that define the inflammatory properties of the vessel wall. They have dynamic control over chemotaxis, adhesion, and extravasation of circulating leukocytes to areas of injury or inflammation (65). Control mechanisms include the expression and release of cytokines and chemokines and cell surface presentation of adhesion molecules in response to a diverse set of environmental elements, including rheologic and oxidative stress, cytokines, hormones, and infection.

\section{Platelet Adhesion to Endothelium}

In the past, numerous studies have shown that platelets can adhere to the intact endothelial monolayer and substantially modulate endothelial cell function (67-75). Thus, under certain pathophysiological circumstances, endothelial denudation and exposure of subendothelial matrix 


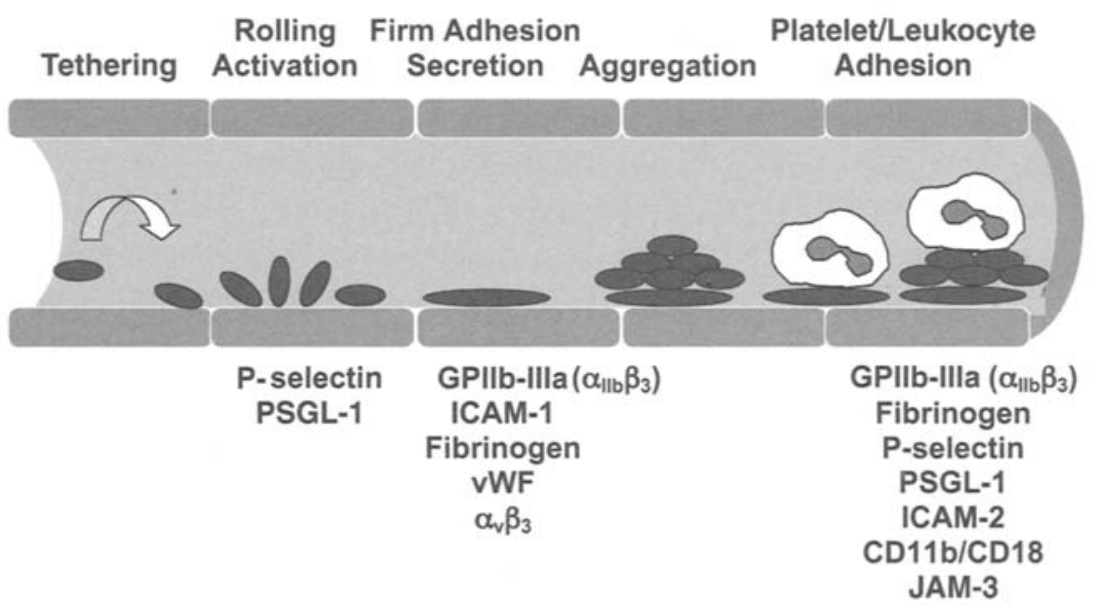

Fig. 2. Platelet adhesion to the endothelium. ICAM, intercellular adhesion molecule; JAM, junctional adhesion molecule; PSGL, P-selectin glycoprotein ligand; vWF, von Willebrand factor.

are not required for platelet adhesion to the vascular wall. Adherent platelets release a variety of proinflammatory mediators and growth hormones and have the potential to modify signaling cascades in vascular cells, inducing the expression of endothelial adhesion receptors and the release of endothelial chemoattractants. In this manner they might regulate the adhesion and infiltration of leukocytes, in particular of monocytes, into the vascular wall, a process thought to play a key role in acute and chronic inflammation. Normal "resting" endothelium represents a nonadhesive and nonthrombogenic surface that prevents extravasation of circulating blood cells (66). In contrast, activated endothelial cells are proadhesive and promote the adhesion of circulating blood platelets. Adhesion of platelets to the intact but activated endothelium in the absence of previous endothelial denudation involves a surface receptor-dependent process that allows "capturing" of circulating platelets toward the vessel wall even under high shear stress. Similar to the recruitment of leukocytes (65), the adhesion of platelets to the vascular endothelial surface is a multistep process, in which platelets are tethered to the vascular wall, followed by platelet rolling and subsequent firm adhesion (Fig. 2).

Whereas the adhesion receptors involved in platelet attachment to the subendothelial matrix, e.g., following rupture of an atherosclerotic plaque, have been well defined during the past decade (Fig. 1), few studies have focused on the molecular determinants that promote the 
interaction between platelets and the intact vascular endothelium. The initial loose contact between circulating platelets and vascular endothelium (platelet rolling) is mediated by selectins, present on both endothelial cells and platelets (76-80). P-selectin (CD62P) is rapidly expressed on the endothelial surface in response to inflammatory stimuli by translocating from membranes of storage granules (Weibel-Palade bodies) to the plasma membrane within seconds. Endothelial P-selectin has been demonstrated to mediate platelet rolling in both arterioles and venules in acute inflammatory processes $(76,79)$. E-selectin, which is also expressed on inflamed endothelial cells, also allows a loose contact between platelets and endothelium in vivo (80). In line with the concept of endothelial inflammation as a trigger for platelet accumulation, the process of platelet rolling does not require previous platelet activation, since platelets from mice lacking $\mathrm{P}$ - and/or E-selectin roll as efficiently as wild-type platelets $(81)$.

So far few studies have addressed the exact nature of the ligands expressed on platelets that bind to endothelial P- or E-selectin. PSGL1 , a glycoprotein that avidly associates with P-selectin, is present predominantly on myeloid cells and mediates leukocyte-endothelium interactions and leukocyte-platelet interactions in vitro and in vivo $(82,83)$.

Another sialomucin that has been identified as a potential counterreceptor for platelet P-selectin is the leucine-rich GPIb-IX-V, the vWF receptor complex. Romo et al. (30) have demonstrated recently that cells expressing P-selectin roll on immobilized GPIb $\alpha$. Platelet rolling on activated endothelium can be inhibited by antibodies against both $\mathrm{P}$ selectin and GPIb $\alpha$, indicating that the vWF receptor mediates platelet adhesion both to the subendothelial matrix and to intact endothelial cells. Future studies are needed to clarify whether the association of GPIb $\alpha$ with P-selectin leads to platelet activation similar to GPIb $\alpha-v W F$ interaction.

Interactions of selectins with their counterreceptors are characterized by high on and off rates, enabling platelets to attach rapidly to the endothelial monolayer with high resistance to tensile stress, explaining why adherent platelets can oppose the drag created by the shear rates present particularly in arterioles. On the other hand, these bonds have an intrinsically high dissociation rate and thus a limited half-life, which results in detachment at the tailing edge of platelets, where the tension is greatest, resulting in forward rotational movement (rolling) from torque imposed by the blood flow. However, because of their biophysical characteristics, selectin-ligand interactions are not sufficient to promote firm adhesion of platelets in the blood stream. This indicates that during rotational movement, new bonds, characterized by low dissociation rates, have to be formed that promote irreversible adhesion. These tighter 
interactions between platelets and the vascular wall involve the interplay of platelets and endothelial integrins as well as immunoglobulin-like adhesion molecules.

Apart from leucine-rich glycoproteins, the integrins are the major group of receptors involved in mediating platelet adhesion to matrix proteins including collagen, vitronectin, fibronectin, and laminin. GPIIbIIIa $\left(\alpha_{\mathrm{IIb}} \beta_{3}\right)$ is the major integrin on platelets and plays a key role in platelet accumulation on activated endothelium. In the presence of soluble fibrinogen, $\alpha_{\mathrm{IIb}} \beta_{3}$ mediates heterotypic cell adhesion to $\alpha_{\mathrm{v}} \beta_{3^{-}}$ expressing cells including endothelial cells $(16,84)$. Moreover, platelets firmly adhere to activated endothelial cells via $\alpha_{\text {IIb }} \beta_{3}$, a mechanism that can be blocked by antagonists of $\beta_{3}$-integrins (16). In vivo, firm platelet adhesion to the endothelium can be inhibited by anti- $\alpha_{\mathrm{IIb}} \beta_{3}$ monoclonal antibody and platelets defective in $\alpha_{\mathrm{IIb}} \beta_{3}$ do not adhere firmly to activated endothelial cells (85). Taken together, these data indicate that, apart from mediating platelet aggregation, the platelet fibrinogen receptor is of paramount importance in mediating firm attachment of platelets to the vascular endothelium (Fig. 2).

Only a few integrins have been reported to be expressed on the luminal side of endothelial cells. Among them, the vitronectin receptor $\left(\alpha_{v} \beta_{3}\right)$ appears to play a crucial role in promoting platelet adhesion. The vitronectin receptor is upregulated in response to endothelial cell activation, e.g., by IL- $1 \beta$ or thrombin $(16,86)$. Inhibition of $\alpha_{\mathrm{v}} \beta_{3}$ attenuates platelet-endothelial cell interaction (16). Hence, both platelet $\alpha_{\mathrm{IIb}} \beta_{3}$ and endothelial $\alpha_{v} \beta_{3}$ are involved in mediating firm adhesion of platelets to the luminal aspect of activated endothelial cells. However, direct binding of $\alpha_{\mathrm{IIb}} \beta_{3}$ to endothelial $\alpha_{\mathrm{v}} \beta_{3}$ has not been reported so far. In fact, heterotypic cell adhesion through $\alpha_{\Pi \mathrm{l}} \beta_{3}$ and $\alpha_{\mathrm{v}} \beta_{3}$ requires the presence of fibrinogen, which bridges the platelet fibrinogen receptor to the endothelial vitronectin receptor (84). Recent evidence suggests that this fibrinogen-dependent bridging mechanism rather than direct receptorligand interactions mediates firm platelet adhesion to the endothelium both in vitro and in vivo (Fig. 3) (85). The affinity of the platelet $\alpha_{\mathrm{IIb}} \beta_{3}$ for its ligand underlies strict regulation and increases with platelet activation (inside out-integrin signaling; see p.120). Although even nonactivated $\alpha_{\text {IIb }} \beta_{3}$ can bind to immobilized fibrinogen, platelet activation during the initial contact between platelets and endothelial cells (platelet rolling), e.g., via GPIb $\alpha$-P-selectin interaction, might enhance the fibrinogen binding capacity of $\alpha_{\mathrm{II}} \beta_{3}$ and thereby facilitate subsequent firm platelet adhesion (30).

Recently, two members of the JAM adhesion receptor family have been identified in platelets, JAM-1 and JAM-3 (36-39). Platelets constitutively express JAM-1 (F11R) and inhibit JAM-1 by blocking mono- 
A

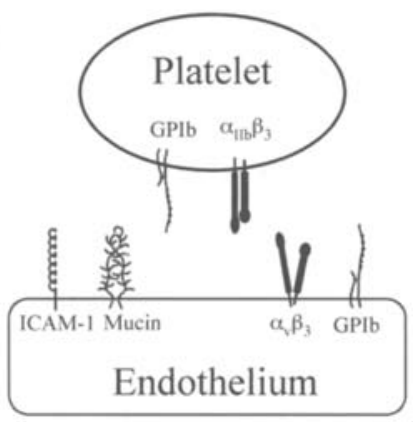

C

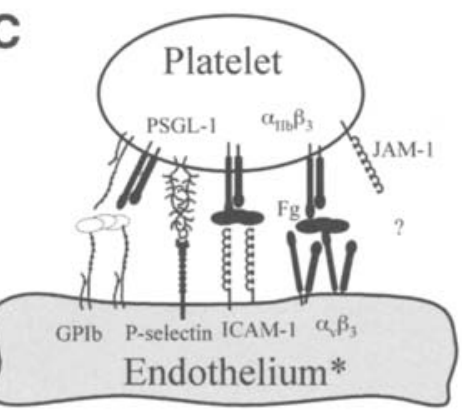

B

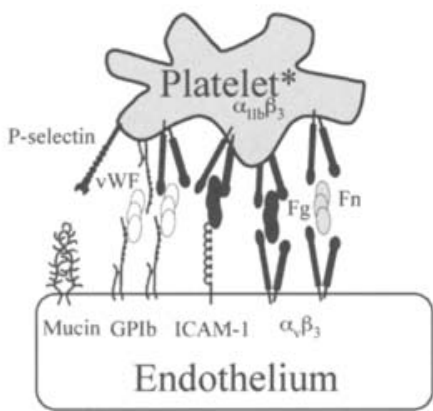

D

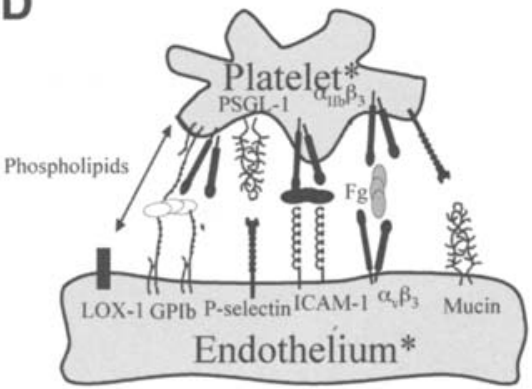

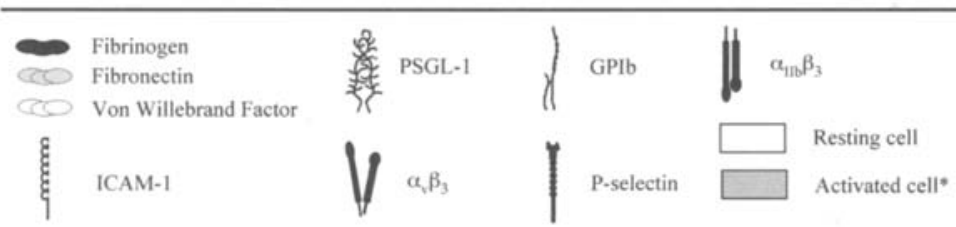

Fig. 3. Various possibilities of platelet interaction with endothelial cells. (A) Resting platelet and resting endothelium; (B) activated platelet and resting endothelium; (C) resting platelet and activated endothelium; (D) both activated platelet and endothelium. Fg, fibrinogen; Fn, fibronectin, ICAM, intercellular adhesion molecule; JAM, junctional adhesion molecule; LOX-1, lectin-like oxidized low-density lipoprotein; PSGL, P-selectin glycoprotein ligand; vWF, von Willebrand factor.

clonal antibody-reduced platelet adhesion to TNF- $\alpha$-treated endothelial cells (Fig. 3).

Apart from the traditional adhesion receptors, scavenger receptors that bind oxidized low-density lipoprotein (oxLDL) appear to be involved in the recruitment of blood cells to the inflamed endothelial surface. The endothelial receptor for oxLDL, lectin-like oxLDL-1 (LOX-1), has been proposed to promote platelet adhesion to the endothelial cell surface (74). Phosphatidylserines, exposed on the surface of activated 


\section{Adhesion}

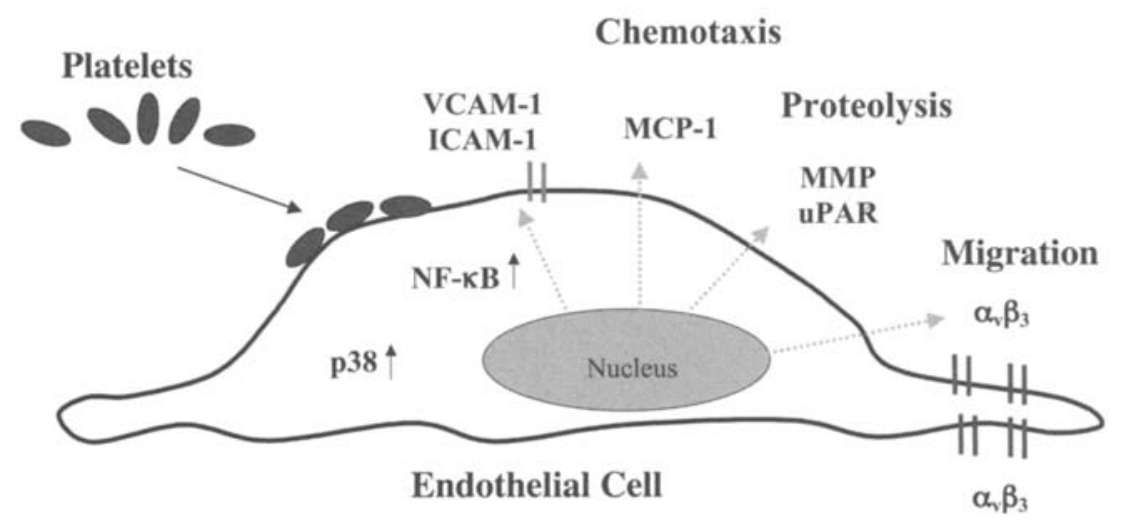

Fig. 4. Platelet-induced endothelial inflammation. ICAM, intercellular adhesion molecule; MCP-1, monocyte chemoattractant protein-1; MMP, matrix metalloproteinase; NF- $\mathrm{\kappa B}$, nuclear factor- $\mathrm{\kappa B}$, uPAR, protease-activated receptor; VCAM, vascular cell adhesion molecule.

platelets, are the ligands for LOX-1. Since LOX-1 expression on endothelial cells is upregulated in vivo by hypertension and hypercholesterolinemia, the scavenger receptor might be important in initiating platelet adhesion to dysfunctional endothelium, especially in the early process of atherosclerosis (Fig. 3).

In summary, platelet-endothelial cell interactions are a multistep process, in which selectins and integrins or immunoglobin-like adhesion receptors play a predominant role. These receptor-dependent plateletendothelial cell interactions allow transcellular communication via soluble mediators and might therefore play an important role in the initiation and progression of vascular inflammation (Fig. 3).

\section{Platelet-Induced Endothelial Activation}

During the adhesion process platelets are activated and release an arsenal of potent proinflammatory and promitogenic substances into the local microenvironment, thereby altering chemotactic, adhesive, and proteolytic properties of endothelial cells (Fig. 4). These platelet-induced alterations of the endothelial phenotype support chemotaxis, adhesion, and transmigration of monocytes to the site of inflammation. Among the various platelet-derived proinflammatory proteins, IL-1 $\beta$ has been identified as a major mediator of platelet-induced activation of endothelial cells $(57,58)$. The IL- $1 \beta$ activity expressed by platelets appears to be associated with the platelet surface $(57,58)$, and coincubation of endothelial cells with thrombin-activated platelets induces IL-1 $\beta$ - 
dependent secretion of IL-6 and IL-8 from endothelial cells. Furthermore, incubation of cultured endothelial cells with thrombin-stimulated platelets significantly enhances the secretion of endothelial monocyte chemoattractant protein-1 (MCP-1) in an IL-1 $\beta$-dependent manner $(86,91)$. MCP-1 belongs to the CC family of chemokines and is thought to play a key role in the regulation of monocyte recruitment to inflamed tissue (91).

However, platelet IL-1 $\beta$ does not only modify endothelial release of chemotactic proteins, it also has the potential to increase endothelial expression of adhesion molecules. Surface expression of intercellular adhesion molecule- 1 (ICAM-1) and $\alpha_{\mathrm{v}} \beta_{3}$ on endothelial cells is significantly enhanced by activated platelets via IL-1 $\beta(86)$. Both enhanced chemokine release and upregulation of endothelial adhesion molecules through platelet-derived IL-1 $\beta$ act in concert and promote neutrophil and monocyte adhesion to the endothelium. IL-1 $1 \beta$-dependent expression of early inflammatory genes, such as MCP-1 or ICAM-1, involves the activation of the transcription factor NF- $\kappa B$. Transient adhesion of platelets to the endothelium initiates degradation of inhibitor of $\mathrm{KB}(\mathrm{I} \kappa \mathrm{B})$ and supports activation of NF- $\kappa B$ in endothelial cells, thereby inducing

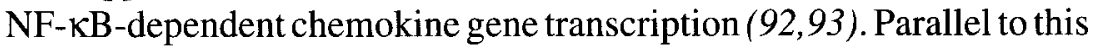
finding, transfection of "decoy" $\mathrm{\kappa B}$ oligonucleotides or a dominantnegative IKB kinase (IKK) mutant attenuates platelet-induced nuclear translocation of NF- $\mathrm{KB}$ and MCP-1 secretion in endothelial cells (93). Likewise, platelet-induced NF- $\kappa \mathrm{B}$-activation was found to be largely reduced by IL- $1 \beta$ antagonists, supporting the notion that platelet IL-1 $\beta$ is the molecular determinant of platelet-dependent activation of the transcription factor.

Activation of NF- $\mathrm{KB}$ involves a cascade of phosphorylation processes. One family of kinases that is involved in NF- $\mathrm{kB}$-dependent gene expression is the mitogen-activated protein (MAP) kinases, such as p38 MAP kinase. In a manner similar to recombinant human IL-1 $\beta$, activated platelets have the potential to induce phosphorylation of p38 MAP kinase. Correspondingly, transfection of a dominant-negative p38 mutant significantly reduced platelet-induced MCP-1 secretion in endothelial cells (94). Taken together, these data indicate that platelet-derived IL- $1 \beta$ initiates NF- $\mathrm{kB}$ dependent expression of chemotactic and adhesive proteins in endothelial cells. In this manner, platelets promote the recruitment of both neutrophils and monocytes to the endothelial cell surface, thus inducing inflammation.

Another platelet-derived chemokine is the regulated on activation, Tcell expressed and secreted chemokine (RANTES), which has been seen to trigger monocyte arrest on inflamed and atherosclerotic endothelium 
(95). Deposition of platelet RANTES induces monocyte recruitment mediated by P-selectin (96). Furthermore, release of platelet-derived CD40 ligand induces inflammatory responses in endothelium. CD154 (CD40L), a 30-33-kDa protein, belongs to the TNF family of cytokines, which includes TNF- $\alpha$ and Fas ligand. CD40L was originally thought to be restricted to $\mathrm{CD}^{+} \mathrm{T}$ lymphocytes, mast cells, and basophils. Henn et al. (46) showed that platelets store $\mathrm{CD} 40 \mathrm{~L}$ in high amounts and release CD40L within seconds following activation in vitro. Ligation of CD40 on endothelial cells by CD40L expressed on the surface of activated platelets increased the release of IL- 8 and MCP-1, the principal chemoattractants for neutrophils and monocytes (46). In addition, platelet $\mathrm{CD} 40 \mathrm{~L}$ enhanced the expression of endothelial adhesion receptors including E-selectin, vascular cell adhesion molecule-1 (VCAM-1), and ICAM-1, all molecules that mediate the attachment of neutrophils, monocytes, and lymphocytes to the inflamed vessel wall. Moreover, CD40L induces endothelial tissue factor expression (97). Hence, like IL$1 \beta, \mathrm{CD} 40 \mathrm{~L}$ expressed on platelets induces endothelial cells to release chemokines and to express adhesion molecules, thereby generating signals for the recruitment of leukocytes in the process of inflammation.

CD40 ligation on endothelial cells, smooth muscle cells, and macrophages initiates the expression and release of matrix-degrading enzymes, the matrix metalloproteinases (MMPs). These enzymes, which degrade extracellular matrix proteins, contribute significantly to the destruction and remodeling of inflammed tissue. Activated platelets release MMP-2 and MMP-9 during aggregation (98). Moreover, adhesion of activated platelets to endothelial cells results in generation and secretion of MMP-9 and of the protease-activated receptor UPAR on cultured endothelium (99). The endothelial release of MMP-9 was dependent on both the fibrinogen receptor GPIIb-IIIa and CD40L because inhibition of either mechanism resulted in reduction of platelet-induced matrix degradation activity of endothelial cells. Moreover, GPIIb-IIIa ligation results in substantial release of CD40L in the absence of any further platelet agonist (100) (Fig. 5). These results suggest that the release of platelet-derived proinflammatory mediators like CD40L is dependent on GPIIb-IIIa-mediated adhesion. This mechanism may be pathophysiologically important for the localization of platelet-induced inflammation of the endothelium at a site of platelet-endothelium adhesion.

\section{PLATELET INTERACTION WITH LEUKOCYTES}

Platelet adhesion to the endothelium or the subendothelial matrix induces platelet activation and the release of substances that are able to cause chemotaxis and migration of circulating leukocytes toward the site 


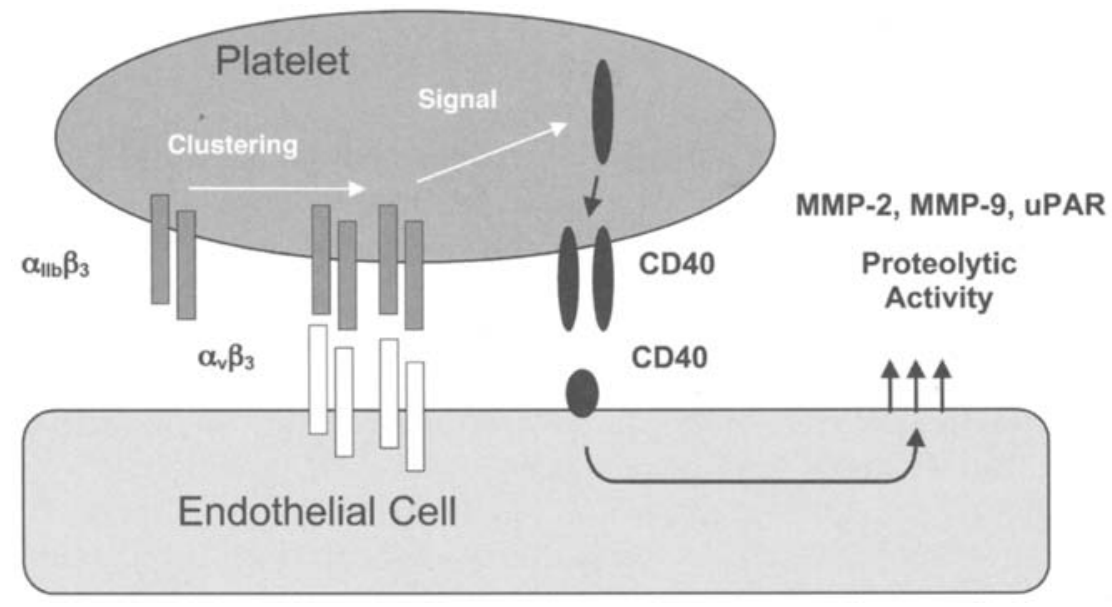

Fig. 5. GPIIb-IIIa-mediated release of CD40 ligand (CD40L) and pericellular proteolysis. MMP, matrix metalloproteinase; uPAR, protease-activated receptor.

of platelets accumulation. Platelets and leukocytes can form heterotypic conjugates, i.e., platelet-leukocyte aggregates, both in vivo and in vitro (101). All leukocytes subpopulations can conjugate platelets (102,103). Among them, monocytes show the greatest, and lymphocytes the least, propensity to form aggregates with platelets. Accumulating evidence indicates that close cell-cell contact mutually regulates platelet and leukocyte functions. Leukocyte-bound platelets may facilitate leukocyte rolling, adhesion, and migration on/through the vessel wall and thus enhance the accumulation of leukocytes at inflammatory sites (104). For example, neutrophil adhesion to cultured endothelial cells, or neutrophil adhesion to damaged arterial segments is enhanced in the presence of platelets (104). Platelet-derived microparticles may also enhance monocyte adhesion to the endothelium (63). Similarly, leukocytes can enhance platelet adhesion to endothelial cells by platelet-leukocyte aggregation. Activated platelets may facilitate leukocyte recruitment into a growing thrombus; leukocytes, in turn, contribute to platelet activation and fibrin deposition (105).

\section{Mechanisms of Platelet Adhesion to Leukocytes}

Like platelet adhesion to the vessel wall, leukocyte recruitment to the vascular endothelium requires multistep adhesive and signaling events including selectin-mediated rolling, leukocyte activation, and integrinmediated firm adhesion and diapedesis (65) (Fig. 6). Several ligandreceptor systems have been found to be involved in platelet-leukocyte aggregation (Fig. 6). Platelet-expressed P-selectin $(106,107)$ and leuko- 


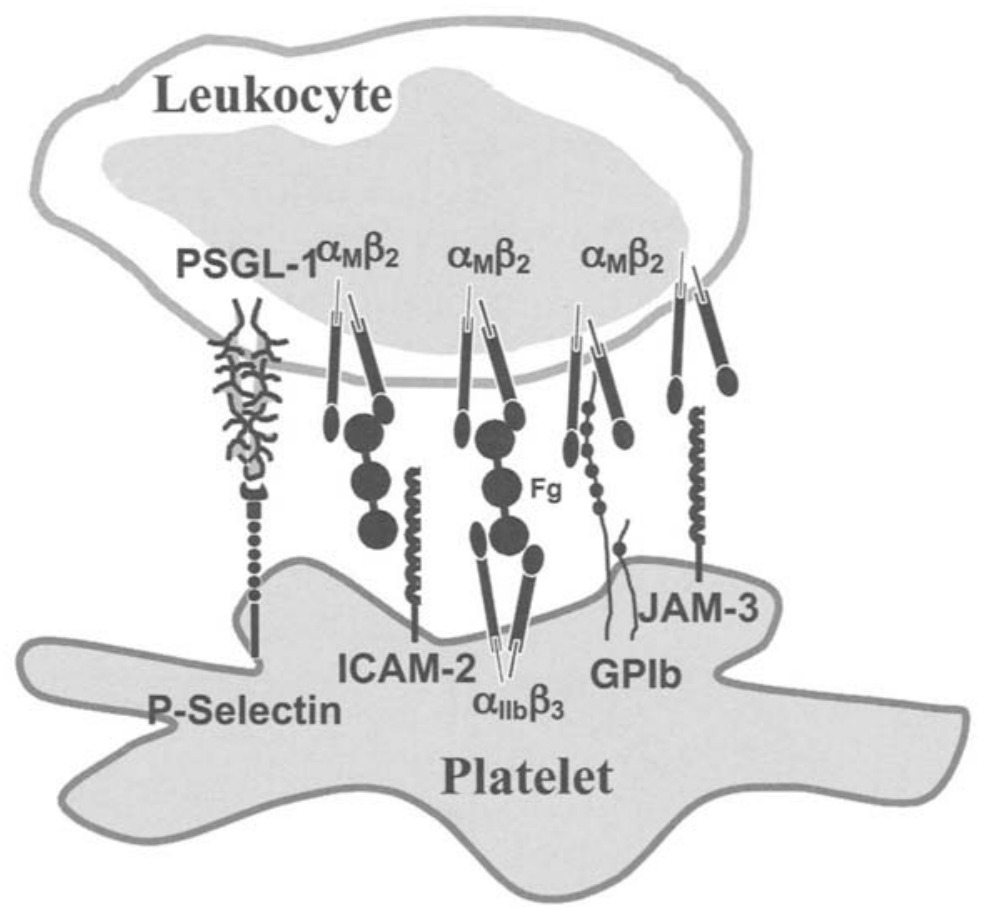

Fig. 6. Receptors that mediate platelet adhesion to leukocytes. ICAM, intercellular adhesion molecule; JAM, junctional adhesion molecule; PSGL, P-selectin glycoprotein ligand.

cyte-expressed PSGL-1/CD15 are the most important receptors for platelet-leukocyte adhesion. The bridging of platelet GPIIb-IIIa and leukocyte $\beta_{2}$-integrins (CD11b/CD18 and CD11c/CD18) by fibrinogen (108) and the ligation of CD36 (on both cell types) via thrombospondin (109) also contribute to platelet-leukocyte adhesion. Furthermore, CD40/ CD40L (108, 109), ICAM-1/ $\beta_{2}$-integrins (87), GPIb $\alpha / M a c-1$, and JAM3/Mac-1 (38) are also involved in platelet-leukocyte adhesion. At sites of platelet adhesion to the endothelium or subendothelium, leukocyte infiltration can also occur through interactions with platelets and fibrin (105).

Platelets either immobilized on a surface or activated in suspension express a complete machinery to recruit leukocytes, as follows: (1) platelet $\mathrm{P}$-selectin is a mediator of the first contact (tethering); (2) interaction of platelet P-selectin with its counterreceptor PSGL-1 on leukocytes induces signaling events relevant for Mac-1 activation; and (3) the activated $\beta_{2}$-integrin (Mac-1) on leukocytes allows and reinforces firm platelet-leukocyte adhesion through binding to counterreceptors (ICAM- 


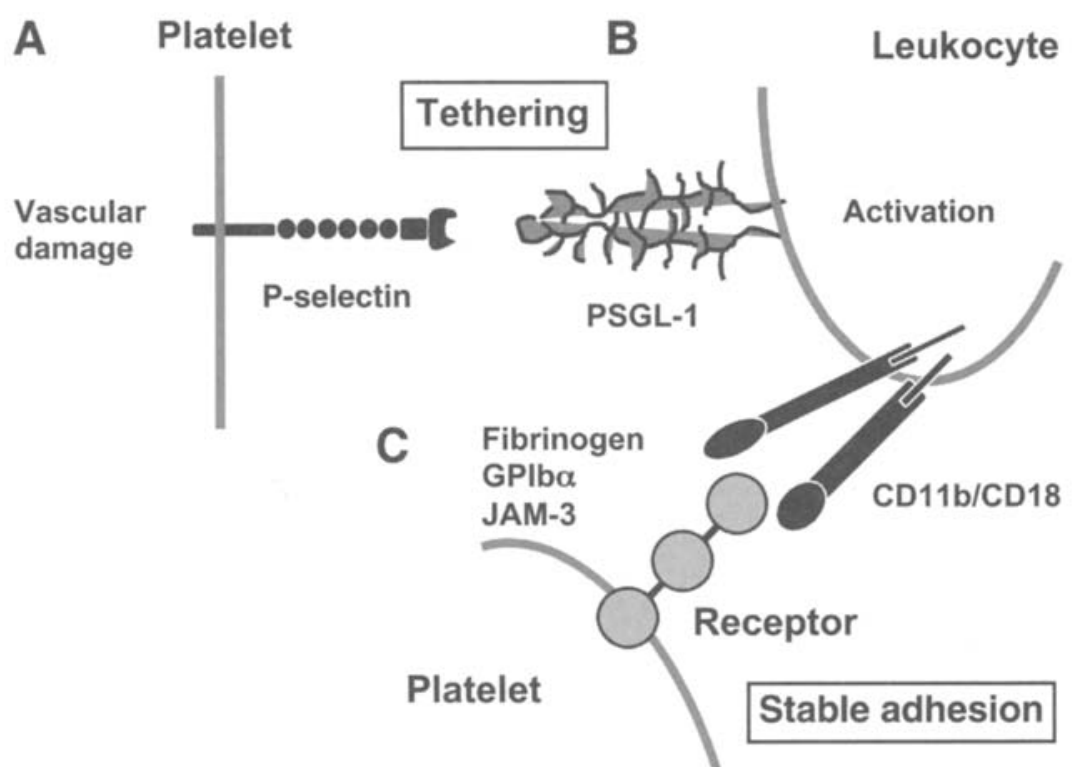

Fig. 7. Platelet-induced activation of leukocytes via P-selectin. (A) Platelet tethering to leukocytes via P-selectin/PSGL-1 adhesion. (B) P-selectin/PSGL1-mediated leukocyte activation. (C) Consolidation of platelet-leukocyte adhesion via interaction of MAC-1 (CD11b/CD18) with platelet-bound fibrinogen or platelet surface-expressed GPIb or junctional adhesion molecule-3 (JAM-3). PSGL, P-selectin glycoprotein ligand.

2, fibrinogen bound to GPIIb-III $\alpha$, GPIb $\alpha$, JAM-3) present on the platelet surface (Fig. 7).

Platelet adhesion to leukocytes enhances the proinflammatory and prothrombotic activities of leukocytes (112). Thus, leukocyte-bound platelets are known to enhance leukocyte adhesion molecule expression, superoxide anion generation, tissue factor expression, and cytokine synthesis $(43,44,113,114)$. These effects seem to be closely regulated by intercellular signaling via adhesion molecule ligation. PSGL-1/Pselectin ligation induces a tyrosine-kinase-dependent signal, which upregulates Mac- 1 expression and enhances $\beta_{2}$-integrin-dependent neutrophil adhesion to ICAM-1 (115). P-selectin/PSGL-1 interaction markedly enhances tissue factor activity in monocytes, and PSGL-1 blockade can inhibit tissue factor expression (116,117). Furthermore, PSGL-1 engagement also mobilizes transcription factor NF- $\kappa \mathrm{B}$ and induces cytokine expression in monocytes (43). Signaling via $\beta_{2}$-integrins is necessary for neutrophil oxidative bursts, and platelets conjugating to neutrophil $\beta_{2}$-integrin via fibrinogen upregulate neutrophil oxidative burst activity (118). $\beta_{2}$-integrin is also involved in the expression of $\beta_{1^{-}}$ 
integrins $\left(\alpha_{4} \beta_{1}\right.$ and $\left.\alpha_{2} \beta_{1}\right)$, which are important in neutrophil adhesion and migration (119) (Fig. 7).

\section{Platelet-Induced Leukocyte Activation Via Soluble Mediators}

Apart from direct cell-cell conjugation, leukocyte function can be influenced by platelet-derived soluble mediators. A number of proteins stored in platelet $\alpha$-granules have been shown to enhance leukocyte activation (Table 2). Platelets contain large amounts of two chemokines, PF-4 and $\beta$-TG, which are stored in $\alpha$-granules. PF- 4 is chemotactic for neutrophils and monocytes and can induce leukocyte adhesion to endothelial cells and degranulation via activation of leukocyte function-associated antigen-1 (LFA-1) (120). $\beta$-TG is the precursor of NAP-2, which stimulates neutrophil chemotaxis, adherence, calcium mobilization, and degranulation of lysosomes $(120,121)$. It is interesting to note that neutrophil-derived cathepsin $G$ is the principal enzyme cleaving $\beta$ thromboglobulin into NAP-2, and that this product then acts on neutrophils themselves (122-125). Platelet $\alpha$-granules also contain PDGF, which may enhance leukocyte adhesion, degranulation, chemotaxis, phagocytosis, and tissue factor expression (126-128). Moreover, platelet-released fibrinogen may induce oxidative bursts in neutrophils by bridging GPIIb-IIIa and CD11c/CD18 (129).

Small molecules stored in platelet dense granules also regulate various aspects of leukocyte function. Adenine nucleotides (ATP and ADP) can induce adhesion, aggregation, and degranulation of neutrophils and monocytes. Adenine and guanine nucleotides have also been shown to evoke superoxide anion production in neutrophils (130). Serotonin may enhance leukocyte rolling and adhesion by upregulating the expression of leukocyte adhesion molecules, such as Mac-1. Activated leukocytes generate PAF, which induces platelet aggregation, platelet adhesion to endothelial cells, and platelet secretion. Platelet-released chemokines, e.g., RANTES, have been reported to induce monocyte adhesion on endothelial cells (95). Other soluble components released from platelet membranes may also activate leukocytes. For instance, soluble CD40L may bind to monocyte CD40 and promote tissue factor expression and cytokine/chemokine production $(97,99)$. Recombinant P-selectin has also been shown to enhance neutrophil phagocytosis by influencing $\beta_{2^{-}}$ integrin function (112).

\section{PLATELETS AND ATHEROSCLEROSIS}

It is increasingly recognized that atherosclerosis is a chronic inflammatory condition that can be converted into an acute clinical event by atherosclerotic plaque progression, plaque rupture, and thrombosis 
(131). Platelets play a major role in atherogenesis and thrombotic events in diseased arteries. Healthy endothelium maintains vascular integrity and provides a nonthrombotic inner layer of the arterial wall. Chronic endothelial injury and inflammation are key features in the pathogenesis of atherosclerosis (131). Cardiovascular risk factors such as hypercholesterolemia, hypertension, smoking, and diabetes result in oxidative stress of the vascular wall, endothelial dysfunction, and platelet hyperactivity (131). Atherosclerosis emerges locally and preferentially at lesion-prone sites (132) that are characterized by decreased shear stress because of nonlaminar, turbulent blood flow at branching vessels or curves. Normal arterial shear stress is atheroprotective, with high expression of nitric oxide synthetase and COX, whereas decreased shear stress is associated with an atherogenic endothelial phenotype, which expresses ICAM-1, MCP-1, and PDGF (132). Several indications suggest that platelets significantly contribute to the inflammatory processes that promote atherosclerotic lesion formation.

Platelets play a key role in thrombotic vascular occlusion at the atherosclerotic plaque leading to acute thrombotic episodes that result in acute coronary syndrome and stroke (1). After the prolonged process of silent plaque evolution, atheromas become susceptible to plaque rupture, leading to platelet adhesion and subsequent activation on the exposed, highly thrombogenic subendothelial surface, which initiates the dreaded clinical complications of thromboischemic episodes $(133,134)$. Enhanced responsiveness of the atherosclerotic plaque to platelets can be triggered, for example, by changes in the shear forces supporting platelet recruitment to the vulnerable plaque. Furthermore, biological changes in the form of chemotaxis of monocytes toward the plaque region, transmigration through the endothelial barrier, macrophage differentiation, phagocytosis, and secretion of proteolytic enzymes (plasminogen activator system, metalloproteinases) appear to contribute substantially to the instability of the plaque.

Over the past few years platelets have been recognized to play a critical role in the chemotaxis and migration of monocytes, thus promoting inflammation and progression of atherosclerosis. Experimental evidence indicates that platelets might contribute significantly to the inflammatory processes that promote atherosclerotic lesion formation. Platelets can adhere directly to the intact endothelial monolayer even in the absence of endothelial disruption (135). During adhesion platelets are activated and release proinflammatory cytokines and chemoattractants (such as IL-1 $\beta, P F-4$, and CD40 ligand). In vitro interactions between platelets and endothelial cells trigger the secretion of chemokines and the expression of adhesion molecules that promote the 
adhesion of leukocytes (Fig. 4). In this manner, the adhesion of platelets to the endothelial surface might generate signals that lead to the recruitment and extravasation of monocytes during atherosclerotic plaque progression, a process of paramount importance for atherogenesis. Moreover, platelets have been found to alter substantially the pericellular proteolytic activity of endothelial cells (activation of metalloproteinases), resulting in extracellular matrix degradation and fibrous cap thinning of a vulnerable lesion (Fig. 5) (98). Thus, in areas of platelet accumulation at lesion-prone sites, an enhanced release of platelet-derived proatherogenic compounds favors atherogenetic changes within the arterial wall and the development of atherosclerotic plaques.

Recently, the occurrence of platelet-derived proatherogenic compounds like PF-4 and NAP-2 in carotid plaques has been documented (136). PF-4 is a potent chemotactic factor for peripheral blood monocytes and has been found to enhance markedly the uptake of oxLDL by macrophages, an important mechanism in the development of unstable atherosclerotic plaques (137). Only recently was it shown that platelet adhesion to the arterial wall is enhanced during atherogenesis (17). Platelet adhesion to endothelium coincides with inflammatory gene expression and precedes atherosclerotic plaque invasion by leukocytes. Prolonged blockade of platelet adhesion in mice deficient in apolipoprotein E profoundly reduced leukocyte accumulation in the arterial intima and attenuated atherosclerotic lesion formation in the carotid artery bifurcation, the aortic sinus, and the coronary arteries (Fig. 8) (17). Moreover, chronic platelet activation accelerates atherosclerosis (18). Thus, platelet-induced inflammation of the vessel wall plays a major role in initiation of the atherogenetic process (Fig. 9).

\section{CONCLUSIONS}

Platelets play a critical role in acute and chronic inflammation. Major advances have been achieved in the understanding of the molecular mechanisms involved in platelet interaction with inflammatory cells. The interaction of platelets with leukocytes and endothelial cells results in substantial activation of these cell types that changes their chemotactic, adhesive and proteolytic properties significantly. Specific cell adhesion receptors such as selectins, immunoglobulin-type receptors, and integrins are involved in regulation of platelet adhesion with inflammatory cells. Therafter, release of platelet-dependent proinflammatory mediators substantially triggers the inflammatory response in the microenvironment of the site of platelet adhesion. Thus, platelet adhesion and subsequent release reaction are critical mechanisms involved in 

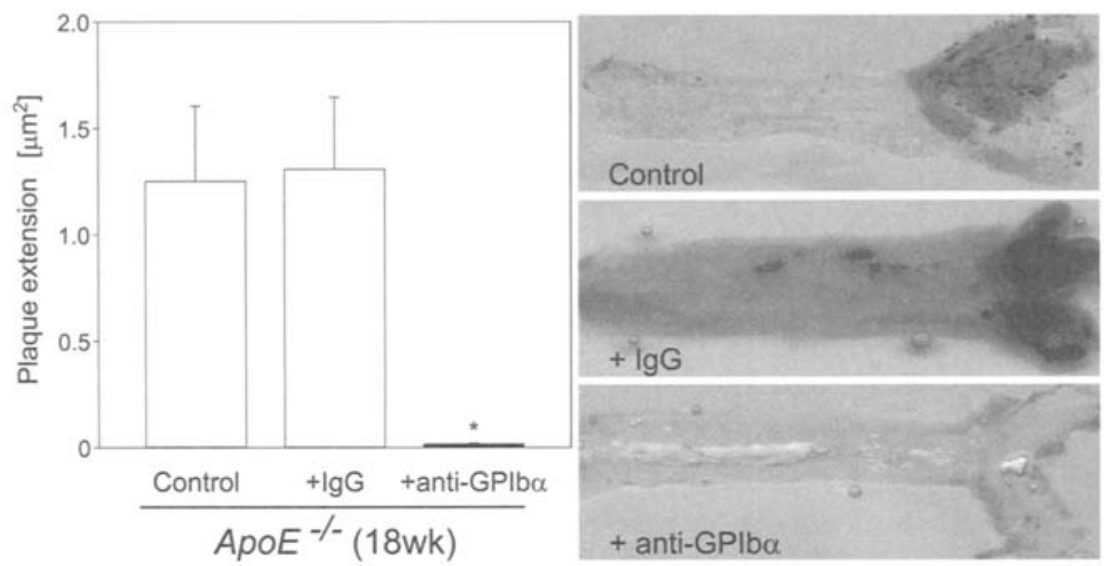

Fig. 8. Chronic GPIb inhibition of platelet-endothelium adhesion substantially inhibits atheroprogression. Plaque extension in the carotid artery in apolipoprotein $\mathrm{E}$ (ApoE)-deficient mice treated or not treated chronically with anti-GPIb monoclonal antibody (17).

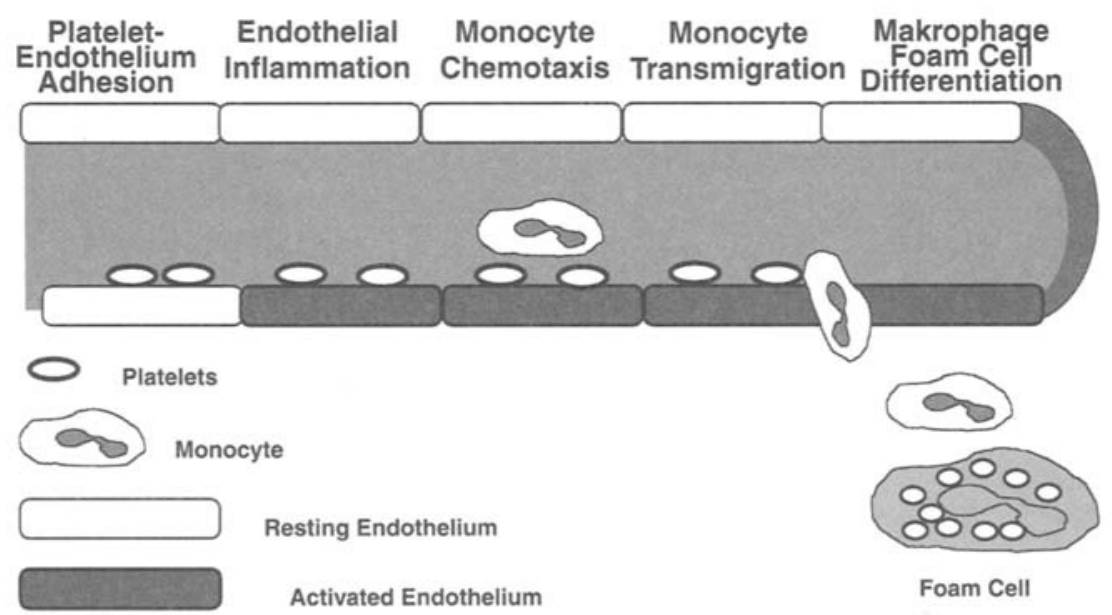

Fig. 9. Critical role of platelet adhesion in atherogenesis.

platelet-mediated inflammation and might represent targets for future therapeutic strategies in a variety of inflammatory diseases.

\section{REFERENCES}

1. Ruggeri ZM. Platelets in atherothrombosis. Nat Med 2002;11:1227-1234.

2. Nieswandt B, Watson SP. Platelet collagen interaction: is GPVI the central receptor? Blood 2003;102:449-461. 
3. Ruggeri ZM. The platelet glycoprotein Ib-IX complex. Prog Hemost Thromb 1991;10:35-68.

4. Ruggeri ZM. Role of von Willebrand factor in platelet thrombus formation. Ann Med 2000;32:2-9.

5. Clemetson KJ. Platelet GPIb-V-IX complex. Thromb Haemost 1997;78:266-270.

6. Gawaz M. Platelet membrane glycoproteins. In: Gawaz M. Blood platelets. Thieme Verlag, Stuttgart, 2001, pp. 30-39.

7. Shattil SJ, Ginsberg MH. Perspectives series: cell adhesion in vascular biology. Integrin signaling in vascular biology. J Clin Invest 1997;100:1-5.

8. Wagner DD, Burger PC. Platelets in inflammation and thrombosis. Arterioscler Thromb Vasc Biol 2003;12:2131-2137.

9. Poubelle PE, Borgeat P. Platelet interactions with other cells related to inflammatory diseases. In: Gresele P, Page CP, Fuster V, Vermylen J, eds. Platelets in thrombotic and non-thrombotic disorders. Cambridge University Press, Cambridge, 2002, pp. 869-884.

10. Klinger $\mathrm{MH}$, Jelkmann W. Role of blood platelets in infection and inflammation. $J$ Interferon Cytokine Res 2002;22:913-922.

11. Gawaz M, Dickfeld T, Bogner C, Fateh-Moghadam S, Neumann FJ. Platelet function in septic multiple organ dysfunction syndrome. Intensive Care Med 1997;4:379-385.

12. Gawaz M, Fateh-Moghadam S, Pilz G, Gurland HJ, Werdan K. Severity of multiple organ failure (MOF) but not of sepsis correlates with irreversible platelet degranulation. Infection 1995;1:16-23.

13. Rinder CS, Bonan JL, Rinder HM, Mathew J, Hines R, Smith BR. Cardiopulmonary bypass induces leukocyte-platelet adhesion. Blood 1992;79:1201-1205.

14. Ott I, Neumann FJ, Gawaz M, Schmitt M, Schomig A. Increased neutrophil-platelet adhesion in patients with unstable angina. Circulation 1996;94:1239-1246.

15. Gawaz M, Neumann FJ, Ott I, Schiessler A, Schomig A. Platelet function in acute myocardial infarction treated with direct angioplasty. Circulation 1996;93:229-237.

16. Gawaz M, Neumann FJ, Dickfeld T, et al. Vitronectin receptor (alpha(v)beta3) mediates platelet adhesion to the luminal aspect of endothelial cells: implications for reperfusion in acute myocardial infarction. Circulation 1997;96:1809-1818.

17. Massberg S, Brand K, Gruner S, et al. A critical role of platelet adhesion in the initiation of atherosclerotic lesion formation. J Exp Med 2002;196:887-896.

18. Huo Y, Schober A, Forlow SB, et al. Circulating activated platelets exacerbate atherosclerosis in mice deficient in apolipoprotein E. Nat Med 2003;1:61-67.

19. Neumann FJ, Ott I, Gawaz M, Puchner G, Schomig A. Neutrophil and platelet activation at balloon-injured coronary artery plaque in patients undergoing angioplasty. J Am Coll Cardiol 1996;27:819-824.

20. McEver RP. Adhesive interactions of leukocytes, platelets, and the vessel wall during hemostasis and inflammation. Thromb Haemost 2001;86:746-756:

21. Williams MJ, Du X, Loftus JC, Ginsberg MH. Platelet adhesion receptors. Semin Cell Biol 1995;6:305-314.

22. Gawaz M. Platelet membrane glycoproteins. In: Gawaz M. Blood platelets. Thieme Verlag, Stuttgart, 2001, pp. 30-39.

23. George JN. Platelets. Lancet 2000;355:1531-1539.

24. Andrews RK, Shen Y, Gardiner EE, Berndt MC. Platelet adhesion receptors and (patho)physiological thrombus formation. Histol Histopathol 2001;16:969-980.

25. Felding-Habermann B. Integrin adhesion receptors in tumor metastasis. Clin Exp Metastasis 2003;20:203-201. 
26. Liddington RC, Ginsberg MH. Integrin activation takes shape. J Cell Biol 2002; 158:833-839.

27. Du X, Ginsberg MH. Integrin alpha IIb beta 3 and platelet function. Thromb Haemost 1997;78:96-100.

28. Hood JD, Cheresh DA. Role of integrins in cell invasion and migration. Nat Rev Cancer 2002;2:91-100.

29. Simon DI, Chen $\mathrm{Z}, \mathrm{Xu} \mathrm{H}$, et al. Platelet glycoprotein Ibalpha is a counterreceptor for the leukocyte integrin Mac-1 (CD11b/CD18). J Exp Med 2000;192:193-204.

30. Romo GM, Dong JF, Schade AJ, et al. The glycoprotein Ib-IX-V complex is a platelet counterreceptor for P-selectin. J Exp Med 1999;190:803-814.

31. McEver RP. Role of selectins in leukocyte adhesion to platelets and endothelium. Ann NY Acad Sci 1994;714:185-189.

32. Furie B, Furie BC. Leukocyte crosstalk at the vascular wall. Thromb Haemost 1997;78:306-309.

33. McEver RP, Cummings RD. Perspectives series: cell adhesion in vascular biology. Role of PSGL-1 binding to selectins in leukocyte recruitment. J Clin Invest 1997; 100:485-491.

34. McEver RP. Adhesive interactions of leukocytes, platelets, and the vessel wall during hemostasis and inflammation. Thromb Haemost 2001;86:746-756.

35. Diacovo TG, deFougerolles AR, Bainton DF, Springer TA. A functional integrin ligand on the surface of platelets: intercellular adhesion molecule-2. J Clin Invest 1994;94:1243-1251.

36. Chavakis T, Preissner KT, Santoso S. Leukocyte trans-endothelial migration: JAMs add new pieces to the puzzle. Thromb Haemost 2003;89:13-17.

37. Gupta SK, Pillarisetti K, Ohlstein EH. Platelet agonist F11 receptor is a member of the immunoglobulin superfamily and identical with junctional adhesion molecule (JAM): regulation of expression in human endothelial cells and macrophages. Life 2000;50:51-56.

38. Santoso S, Sachs UJ, Kroll H, et al. The junctional adhesion molecule 3 (JAM-3) on human platelets is a counterreceptor for the leukocyte integrin Mac-1. J Exp Med 2002;196:679-691.

39. Babinska A, Kedees MH, Athar H, et al. F11-receptor (F11R/JAM) mediates platelet adhesion to endothelial cells: role in inflammatory thrombosis. Thromb Haemost 2002;88:843-850.

40. Gear AR, Camerini D. Platelet chemokines and chemokine receptors: linking hemostasis, inflammation, and host defense. Microcirculation 2003;10:335-350.

41. Rendu F, Brohard-Bohn B. The platelet release reaction: granules' constituents, secretion and functions. Platelets 2001;12:261-273.

42. Harrison P, Cramer EM. Platelet alpha-granules. Blood Rev 1993;7:52-62.

43. Weyrich AS, Elstad MR, et al. Activated platelets signal chemokine synthesis by human monocytes. J Clin Invest 1996;97:1525-1534.

44. Neumann FJ, Marx N, Gawaz M, et al. Induction of cytokine expression in leukocytes by binding of thrombin-stimulated platelets. Circulation 1997;95:2387-2394.

45. Gawaz M, Neumann FJ, Dickfeld T, et al. Activated platelets induce monocyte chemotactic protein-1 secretion and surface expression of intercellular adhesion molecule-1 on endothelial cells. Circulation 1998;98:1164-1167.

46. Henn V, Slupsky JR, Grafe M, et al. CD40 ligand on activated platelets triggers an inflammatory reaction of endothelial cells. Nature 1998;391:591-594.

47. Boogaerts MA, Yamada O, Jacob HS, Moldow CF. Enhancement of granulocyteendothelial cell adherence and granulocyte-induced cytotoxicity by platelet release products. Proc Natl Acad Sci USA 1982;79:7019-7023. 
48. Laberge S, Cruikshank WW, Beer DJ, Center DM. Secretion of IL-16 (lymphocyte chemoattractant factor) from serotonin-stimulated CD8+ T cells in vitro. J Immunol 1996;156:310-315.

49. Sandler JA, Gallin JI, Vaughan M. Effects of serotonin, carbamylcholine, and ascorbic acid on leukocyte cyclic GMP and chemotaxis. J Cell Biol 1975;67:480-484.

50. Momi S, Gresele P. Platelets and chemotaxis. In: Gresele P, Page C, Fuster V, Vermylen J, eds. Platelets in thrombotic and non-thrombotic disorders. Cambridge University Press, Cambridge, 2002, pp. 393-411.

51. Brandt E, Petersen F, Ludwig A, Ehlert JE, Bock L, Flad HD. The betathromboglobulins and platelet factor 4: blood platelet-derived CXC chemokines with divergent roles in early neutrophil regulation. J Leukoc Biol 2000;67:471-478.

52. Power CA, Clemetson JM, Clemetson KJ, Wells TN. Chemokine and chemokine receptor mRNA expression in human platelets. Cytokine 1995;7:479-482.

53. Kronemann N, Bouloumi A, Bassus S, Kirchmaier CM, Busse R, Schini-Kerth VB. Aggregating human platelets stimulate expression of vascular endothelial growth factor in cultured vascular smooth muscle cells through a synergistic effect of transforming growth factor-beta(1) and platelet-derived growth factor(AB). Circulation 1999; 100:855-856.

54. Dell'Angelica EC, Mullins C, Caplan S, Bonifacino JS. Lysosome-related organelles. FASEB J 2000;14:1265-1278.

55. Lindemann S, Tolley ND, Dixon DA, et al. Activated platelets mediate inflammatory signaling by regulated interleukin l beta synthesis. J Cell Biol 2001;154:485-490.

56. Hermann A, Rauch BH, Braun M, Schror K, Weber AA. Platelet CD40 ligand (CD40L)-subcellular localization, regulation of expression, and inhibition by clopidogrel. Platelets 2001;12:74-78.

57. Hawrylowicz CM, Howells GL, Feldmann M. Platelet-derived interleukin 1 induces human endothelial adhesion molecule expression and cytokine production. J Exp Med 1991;174:785-790.

58. Kaplanski G, Porat R, Aiura K, Erban JK, Gelfand JA, Dinarello CA. Activated platelets induce endothelial secretion of interleukin-8 in vitro via an interleukin-1mediated event. Blood 1993;81:2492-2495.

59. Andre P, Prasad KS, Denis CV, et al. CD40L stabilizes arterial thrombi by a beta3 integrin-dependent mechanism. Nat Med 2002;8:247-252.

60. Siess W. Athero- and thrombogenic actions of lysophosphatidic acid and sphingosine-1-phosphate. Biochim Biophys Acta 2002;1582:204-215.

61. Denizot Y. Platelet-activating factor. In: Bruchhausen FV, Authi KS, Walter U, eds. Platelets and their factors. Springer Verlag, Heidelberg, 1997, pp. 483-496.

62. Halushka PV, Pawate S, Martin ML. Thromboxane A2 and other eicosanoids. In: Bruchhausen FV, Authi KS, Walter U, eds. Platelets and their factors. Springer Verlag, Heidelberg, 1997.

63. Barry OP, FitzGerald GA. Mechanisms of cellular activation by platelet microparticles. Thromb Haemost 1999;82:794-800.

64. Palmetshofer A, Robson SC, Nehls V. Lysophosphatidic acid activates nuclear factor kappa B and induces proinflammatory gene expression in endothelial cells. Thromb Haemost 1999;82:1532-1537.

65. Springer TA. Traffic signals for lymphocyte recirculation and leukocyte emigration: the multistep paradigm. Cell 1994;76:301-314.

66. Sporn LA, Huber P. Endothelial cell biology. In: Colman RW, Hirsh J, Marder VJ, Clowes AW, George JN, eds. Hemostasis and thrombosis. Basic principles and clinical practice, 4th ed. Lippincott Williams \& Wilkins, Philadelphia, 2001, pp. 615-623. 
67. Venturini CM, Kaplan JE. Thrombin induces platelet adhesion to endothelial cells. Semin Thromb Hemost 1992;18:275-283.

68. Kaplan JE, Moon DG, Weston LK, et al. Platelets adhere to thrombin-treated endothelial cells in vitro. Am J Physiol 1989;257:423-433.

69. Etingin OR, Silverstein RL, Hajjar DP. von Willebrand factor mediates platelet adhesion to virally infected endothelial cells. Proc Natl Acad Sci USA 1993;90:5153-5156.

70. Itoh Y, Tomita M, Tanahashi N, Takeda H, Yokoyama M, Fukuuchi Y. Platelet adhesion to aortic endothelial cells in vitro after thrombin treatment: observation with video-enhanced contrast microscopy. Thromb Res 1998;91:15-22.

71. Reininger AJ, Korndorfer MA, Wurzinger LJ. Adhesion of ADP-activated platelets to intact endothelium under stagnation point flow in vitro is mediated by the integrin alphallbeta3. Thromb Haemost 1998;79:998-1003.

72. Li JM, Podolsky RS, Rohrer MJ, et al. Adhesion of activated platelets to venous endothelial cells is mediated via GPIIb/IIIa. J Surg Res 1996;61:543-548.

73. Bombeli T, Schwartz BR, Harlan JM. Adhesion of activated platelets to endothelial cells: evidence for a GPIIbIIIa-dependent bridging mechanism and novel roles for endothelial intercellular adhesion molecule 1 (ICAM-1), alphavbeta3 integrin, and GPIbalpha. J Exp Med 1998;187:329-333.

74. Kakutani M, Masaki T, Sawamura T. A platelet-endothelium interaction mediated by lectin-like oxidized low-density lipoprotein receptor-1. Proc Natl Acad Sci USA 2000;97:360-364.

75. Bombeli T, Schwartz BR, Harlan JM. Endothelial cells undergoing apoptosis become proadhesive for nonactivated platelets. Blood 1999;93:3831-3838.

76. Frenette PS, Johnson RC, Hynes RO, Wagner DD. Platelets roll on stimulated endothelium in vivo: an interaction mediated by endothelial P-selectin. Proc Natl Acad Sci USA 1995;92:7450-7454.

77. Johnson RC, Mayadas TN, Frenette PS, et al. Blood cell dynamics in P-selectindeficient mice. Blood 1995;86:1106-1114.

78. Subramaniam M, Frenette PS, Saffaripour S, Johnson RC, Hynes RO, Wagner DD. Defects in hemostasis in P-selectin-deficient mice. Blood 1996;87:1238-1242.

79. Frenette PS, Moyna C, Hartwell DW, Lowe JB, Hynes RO, Wagner DD. Plateletendothelial interactions in inflamed mesenteric venules. Blood 1998;91:1318-1324.

80. Frenette PS, Subbarao S, Mazo IB, von Andrian UH, Wagner DD. Endothelial selectins and vascular cell adhesion molecule-1 promote hematopoietic progenitor homing to bone marrow. Proc Natl Acad Sci USA 1998;95:14423-1448.

81. Massberg S, Enders G, Leiderer R, et al. Platelet-endothelial cell interactions during ischemia/reperfusion: the role of P-selectin. Blood 1998;92:507-515.

82. Laszik Z, Jansen PJ, Cummings RD, Tedder TF, McEver RP, Moore KL. P-selectin glycoprotein ligand-1 is broadly expressed in cells of myeloid, lymphoid, and dendritic lineage and in some nonhematopoietic cells. Blood 1996;88:3010-3012.

83. Frenette PS, Denis CV, Weiss L, et al. P-Selectin glycoprotein ligand 1 (PSGL-1) is expressed on platelets and can mediate platelet-endothelial interactions in vivo. J Exp Med 2000;191:1413-1422.

84. Gawaz MP, Loftus JC, Bajt ML, Frojmovic MM, Plow EF, Ginsberg MH. Ligand bridging mediates integrin alpha Ilb beta 3 (platelet GPIIB-IIIA) dependent homotypic and heterotypic cell-cell interactions. J Clin Invest 1991;88:1128-1134.

85. Massberg S, Enders G, Matos FC, et al. Fibrinogen deposition at the postischemic vessel wall promotes platelet adhesion during ischemia-reperfusion in vivo. Blood 1999;94:3829-3838.

86. Gawaz M, Brand K, Dickfeld T, et al. Platelets induce alterations of chemotactic and adhesive properties of endothelial cells mediated through an interleukin-1-dependent mechanism. Implications for atherogenesis. Atherosclerosis 2000;148:75-85. 
87. Languino LR, Duperray A, Joganic KJ, Fornaro M, Thornton GB, Altieri DC. Regulation of leukocyte-endothelium interaction and leukocyte transendothelial migration by intercellular adhesion molecule 1-fibrinogen recognition. Proc Natl Acad Sci USA 1995;92:1505-1509.

88. Altieri DC, Duperray A, Plescia J, Thornton GB, Languino LR. Structural recognition of a novel fibrinogen gamma chain sequence (117-133) by intercellular adhesion molecule-1 mediates leukocyte-endothelium interaction. J Biol Chem 1995;270:696-699.

89. Sriramarao P, Languino LR, Altieri DC. Fibrinogen mediates leukocyte-endothelium bridging in vivo at low shear forces. Blood 1996;88:3416-3423.

90. Massberg S, Vogt F, Dickfeld T, Brand K, Page S, Gawaz M. Activated platelets trigger an inflammatory response and enhance migration of aortic smooth muscle cells. Thromb Res 2003;110:187-194.

91. Lu B, Rutledge BJ, Gu L, et al. Abnormalities in monocyte recruitment and cytokine expression in monocyte chemoattractant protein 1-deficient mice. J Exp Med 1998; 187:601-608.

92. Gawaz M, Page S, Massberg S, et al. Transient platelet interaction induces MCP1 production by endothelial cells via I kappa B kinase complex activation. Thromb Haemost 2002;88:307-314.

93. Gawaz M, Neumann FJ, Dickfeld T, et al. Activated platelets induce monocyte chemotactic protein-1 secretion and surface expression of intercellular adhesion molecule-1 on endothelial cells. Circulation 1998;98:1164-1171.

94. Dickfeld T, Lengyel E, May AE, et al. Transient interaction of activated platelets with endothelial cells induces expression of monocyte-chemoattractant protein-1 via a p38 mitogen-activated protein kinase mediated pathway. Implications for atherogenesis. Cardiovasc Res 2001;41:189-199.

95. von Hundelshausen $P$, Weber KS, Huo Y, et al. RANTES deposition by platelets triggers monocyte arrest on inflamed and atherosclerotic endothelium. Circulation 2001;103:1772-1777.

96. Schober A, Manka D, von Hundelshausen P, et al. Deposition of platelet RANTES triggering monocyte recruitment requires $\mathrm{P}$-selectin and is involved in neointima formation after arterial injury. Circulation 2002;106:1523-1529.

97. Slupsky JR, Kalbas M, Willuweit A, Henn V, Kroczek RA, Muller-Berghaus G. Activated platelets induce tissue factor expression on human umbilical vein endothelial cells by ligation of CD40. Thromb Haemost 1998;80:1008-1014.

98. Fernandez-Patron C, Martinez-Cuesta MA, Salas E, et al. Differential regulation of platelet aggregation by matrix metalloproteinases- 9 and -2 . Thromb Haemost 1999;82:1730-1735.

99. May AE, Kalsch T, Massberg S, Herouy Y, Schmidt R, Gawaz M. Engagement of glycoprotein IIb/IIIa (alpha(IIb)beta3) on platelets upregulates CD40L and triggers CD40L-dependent matrix degradation by endothelial cells. Circulation 2002;106:2111-2117.

100. Nannizzi-Alaimo L, Alves VL, Phillips DR. Inhibitory effects of glycoprotein IIb/ IIIa antagonists and aspirin on the release of soluble CD40 ligand during platelet stimulation. Circulation 2003;107:1123-1128.

101. Bazzoni G, Dejana E, Del Maschio A. Platelet-neutrophil interactions. Possible relevance in the pathogenesis of thrombosis and inflammation. Haematologica 1991;76:491-499. 
102. Rinder HM, Bonan JL, Rinder CS, Ault KA, Smith BR. Activated and unactivated platelet adhesion to monocytes and neutrophils. Blood 1991;78:1760-1769.

103. Rinder HM, Bonan JL, Rinder CS, Ault KA, Smith BR. Dynamics of leukocyteplatelet adhesion in whole blood. Blood 1991;78:1730-1737.

104. Weber C, Springer TA. Neutrophil accumulation on activated, surface-adherent platelets in flow is mediated by interaction of Mac-1 with fibrinogen bound to $\alpha$ Iib $\beta 3$ and stimulated by platelet-activating factor. J Clin Invest 1997;100:2085-2093.

105. Palabrica T, Lobb R, Furie BC, et al. Leukocyte accumulation promoting fibrin deposition is mediated in vivo by P-selectin on adherent platelets. Nature 1992;359:848-851.

106. Larsen E, Palabrica T, Sajer S, et al. PADGEM-dependent adhesion of platelets to monocytes and neutrophils is mediated by a lineage-specific carbohydrate, LNF III (CD15). Cell 1990;63:467-474.

107. Hamburger SA, McEver RP. GMP-140 mediates adhesion of stimulated platelets to neutrophils. Blood 1990;75:550-554.

108. Konstantopoulos K, Neelamegham S, Burns AR, et al. Venous levels of shear support neutrophil-platelet adhesion and neutrophil aggregation in blood via $\mathbf{P}$ selectin and beta2-integrin. Circulation 1998;98:873-882.

109. Silverstein RL, Asch AS, Nachman RL. Glycoprotein IV mediates thrombospondindependent platelet-monocyte and platelet-U937 cell adhesion. J Clin Invest 1989;84:546-552.

110. Alderson MR, Armitage RJ, Tough TW, Strockbine L, Fanslow WC, Spriggs MK. CD40 expression by human monocytes: regulation by cytokines and activation of monocytes by the ligand for CD40. J Exp Med 1993;178:669-674.

111. Inwald DP, McDowall A, Peters MJ, Callard RE, Klein NJ. CD40 is constitutively expressed on platelets and provides a novel mechanism for platelet activation. Circ Res 2003;92:1041-1048.

112. Blanks JE, Moll T, Eytner R, Vestweber D. Stimulation of P-selectin glycoprotein ligand- 1 on mouse neutrophils activates beta 2 -integrin mediated cell attachment to ICAM-1. Eur J Immunol 1998;28:433-443.

113. Nagata K, Tsuji T, Todoroki N, et al. Activated platelets induce superoxide anion release by monocytes and neutrophils through P-selectin (CD62). J Immunol 1993;151:3267-3273.

114. Østerud B. The role of platelets in decrypting monocyte tissue factor. Dis Mon 2003;49:7-13.

115. Evangelista V, Manarini S, Sideri R, et al. Platelet/polymorphonuclear leukocyte interaction: P-selectin triggers protein-tyrosine phosphorylation-dependent CD1 lb/ CD18 adhesion: role of PSGL-1 as a signalling molecule. Blood 1999;93:876-885.

116. Celi A, Pellegrini G, Lorenzet R, et al. P-selectin induces the expression of tissue factor on monocytes. Proc Natl Acad Sci USA 1994;91:8767-8771.

117. Østerud B. Cellular interactions in tissue factor expression by blood monocytes. Blood Coagul Fibrinolysis 1995;6(suppl):S20-S25.

18. Ruf A, Patscheke H. Platelet-induced neutrophil activation: platelet-expressed fibrinogen induces the oxidative burst in neutrophils by an interaction with CD11C/ CD18. Br J Haematol 1995;90:791-796.

119. Werr J, Eriksson EE, Hedqvist P, Lindbom L. Engagement of beta2 integrins induces surface expression of betal integrin receptors in human neutrophils. J Leuk Biol 2000;68:553-560.

120. Brandt E, Petersen F, Ludwig A, Ehlert JE, Bock L, Flad HD. The betathromboglobulins and platelet factor 4: blood platelet-derived CXC chemokines with divergent roles in early neutrophil regulation. J Leuk Biol 2000;67:471-478. 
121. Petersen F, Bock L, Flad HD, Brandt E. Platelet factor 4-induced neutrophil-endothelial cell interaction: involvement of mechanisms and functional consequences different from those elicited by interleukin-8. Blood 1999;94:4020-4028.

122. Leonard EJ, Yoshimura T, Rot A, et al. Chemotactic activity and receptor binding of neutrophil attractant/activation protein-1 (NAP-1) and structurally related host defense cytokines: interaction of NAP-2 with the NAP-1 receptor. J Leuk Biol 1991;49:258-265.

123. Walz A, Dewald B, von Tscharner V, Baggiolini M. Effects of the neutrophilactivating peptide NAP-2, platelet basic protein, connective tissue-activating peptide III and platelet factor 4 on human neutrophils. J Exp Med 1989;170:1745-1750.

124. Walz A, Meloni F, Clark-Lewis I, von Tscharner V, Baggiolini M. $\left[\mathrm{Ca}^{2+}\right]$ i changes and respiratory burst in human neutrophils and monocytes induced by NAP-1/ interleukin-8, NAP-2, and gro/MGSA. J Leuk Biol 1991;50:279-286.

125. Harter L, Petersen F, Flad HD, Brandt E. Connective tissue-activating peptide III desensitizes chemokine receptors on neutrophils. Requirement for proteolytic formation of the neutrophil-activating peptide 2. J Immunol 1994;153:5698-5708.

126. Shure D, Senior RM, Griffin GL, Deuel TF. PDGF AA homodimers are potent chemoattractants for fibroblasts and neutrophils, and for monocytes activated by lymphocytes or cytokines. Biochem Biophys Res Commun 1992;186:1510-1514.

127. Tzeng DY, Deuel TF, Huang JS, Baehner RL. Platelet-derived growth factor promotes human peripheral monocyte activation. Blood 1985;66:179-183.

128. Ernofsson M, Siegbahn A. Platelet-derived growth factor-BB and monocyte chemotactic protein-1 induce human peripheral blood monocytes to express tissue factor. Thromb Res 1996;83:307-320.

129. Ruf A, Schlenk RF, Maras A, Morgenstern E, Patscheke H. Contact-induced neutrophil activation by platelets in human cell suspensions and whole blood. Blood 1992;80:1238-1246.

130. Freyer DR, Boxer LA, Axtell RA, Todd RF. Stimulation of human neutrophil adhesive properties by adenine nucleotides. J Immunol 1988;141:580-586.

131. Lusis AJ. Atherosclerosis. Nature 2000;407:233-241.

132. Libby P. Inflammation in atherosclerosis. Nature 2002;420:868-874.

133. Naghavi M, Libby P, Falk E, et al. From vulnerable plaque to vulnerable patient: a call for new definitions and risk assessment strategies: Part I. Circulation 2003;108:1664-1672.

134. Corti R, Farkouh ME, Badimon JJ. The vulnerable plaque and acute coronary syndromes. Am J Med 2002;113:668-680.

135. Sachais BS. Platelet-endothelial interactions in atherosclerosis. Curr Atheroscler Rep 2001;3:412-416.

136. Pitsilos S, Hunt J, Mohler ER, et al. Platelet factor 4 localization in carotid atherosclerotic plaques: correlation with clinical parameters. Thromb Haemost 2003;90:1112-1120.

137. Nassar T, Sachais BS, Akkawi S, et al. Platelet factor 4 enhances the binding of oxidized low-density lipoprotein to vascular wall cells. J Biol Chem 2003;278:6187-6193. 